SANDIA REPORT

SAND2011-3521

Unlimited Release

Printed May 2011

\title{
River Meander Modeling and Confronting Uncertainty
}

Ari Posner

Prepared by

Sandia National Laboratories

Albuquerque, New Mexico 87185

Sandia National Laboratories is a multi-program laboratory, managed and operated by Sandia Corporation, a wholly owned subsidiary of Lockheed Martin Corporation, for the U.S. Department of Energy's National Nuclear Security Administration under contract DE-AC04-94AL85000.

Approved for public release; further dissemination unlimited.

\section{Iit Sandia National Laboratories}


Issued by Sandia National Laboratories, operated for the United States Department of Energy by Sandia Corporation.

NOTICE: This report was prepared as an account of work sponsored by an agency of the United States Government. Neither the United States Government, nor any agency thereof, nor any of their employees, nor any of their contractors, subcontractors, or their employees, make any warranty, express or implied, or assume any legal liability or responsibility for the accuracy, completeness, or usefulness of any information, apparatus, product, or process disclosed, or represent that its use would not infringe privately owned rights. Reference herein to any specific commercial product, process, or service by trade name, trademark, manufacturer, or otherwise, does not necessarily constitute or imply its endorsement, recommendation, or favoring by the United States Government, any agency thereof, or any of their contractors or subcontractors. The views and opinions expressed herein do not necessarily state or reflect those of the United States Government, any agency thereof, or any of their contractors.

Printed in the United States of America. This report was directly reproduced from the best available copy.

Available to DOE and DOE contractors from:

U.S. Department of Energy

Office of Scientific and Technical Information

P.O. Box 62

Oak Ridge, TN 37831

Telephone: $\quad(865) 576-8401$

Facsimile: $\quad(865) 576-5728$

E-Mail: reports@adonis.osti.gov

Online ordering: http://www.osti.gov/bridge

Available to the public from:

U.S. Department of Commerce

National Technical Information Service

5285 Port Royal Rd

Springfield, VA 22161

Telephone: $\quad$ (800)553-6847

Facsimile: (703)605-6900

E-Mail: orders@ntis.fedworld.gov

Online order: http://www.ntis.gov/help/ordermethods.asp?loc=7-4-0\#online

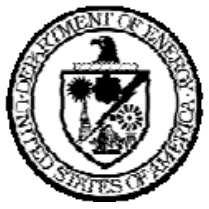




\title{
River Meander Modeling and Confronting Uncertainty
}

\author{
Ari J. Posner, \\ Department of Hydrology and Water Resources \\ University of Arizona \\ 1133 E James E. Rogers Way Rm 122 \\ PO Box 210011 \\ Tucson, AZ 85721
}

\begin{abstract}
This study examines the meandering phenomenon as it occurs in media throughout terrestrial, glacial, atmospheric, and aquatic environments. Analysis of the minimum energy principle, along with theories of Coriolis forces (and random walks to explain the meandering phenomenon) found that these theories apply at different temporal and spatial scales. Coriolis forces might induce topological changes resulting in meandering planforms. The minimum energy principle might explain how these forces combine to limit the sinuosity to depth and width ratios that are common throughout various media.

The study then compares the first order analytical solutions for flow field by Ikeda, et al. (1981) and Johannesson and Parker (1989b). Ikeda's et al. linear bank erosion model was implemented to predict the rate of bank erosion in which the bank erosion coefficient is treated as a stochastic variable that varies with physical properties of the bank (e.g., cohesiveness, stratigraphy, or vegetation density). The developed model was used to predict the evolution of meandering planforms. Then, the modeling results were analyzed and compared to the observed data. Since the migration of a meandering channel consists of downstream translation, lateral expansion, and downstream or upstream rotations several measures are formulated in order to determine which of the resulting planforms is closest to the experimental measured one. Results from the deterministic model highly depend on the calibrated erosion coefficient. Since field measurements are always limited, the stochastic model yielded more realistic predictions of meandering planform evolutions. Due to the random nature of bank erosion coefficient, the meandering planform evolution is a stochastic process that can only be accurately predicted by a stochastic model.
\end{abstract}


Ari Posner was a recipient of Sandia's Campus Executive Fellowship at the University of Arizona. Support for this fellowship program is derived through Sandia's Laboratory Directed Research and Development (LDRD) program. 


\section{Acknowledgement}

We thank Dr. Vince Tidwell of Sandia National Laboratories for ideas, assistance, and patience. We would also like to thank Dr. Hoshin Gupta for his help with the stochastic simulation and discussions of model structure. The National Science Foundation is also appreciated for their support of Dr. Jennifer Duan. Support for this research was provided by Sandia National Labs Laboratory Research and Development Program through a partnership with the Department of Hydrology and Water Resources at the University of Arizona, Tucson, Arizona, and by the Sustainability of Semi-Arid Hydrology and Riparian Areas Research Center. 


\section{Table of Contents}

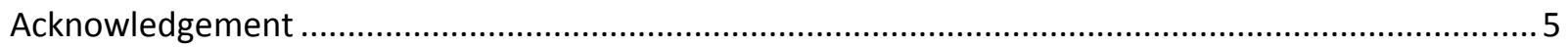

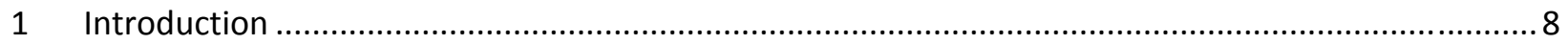

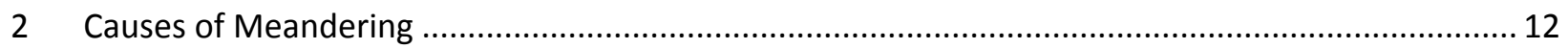

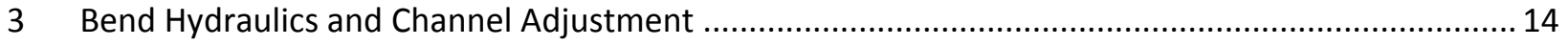

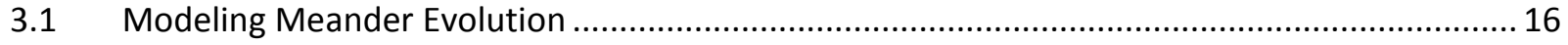

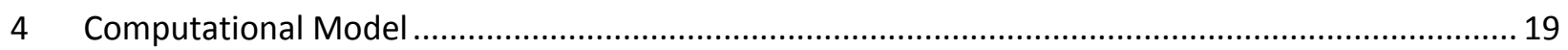

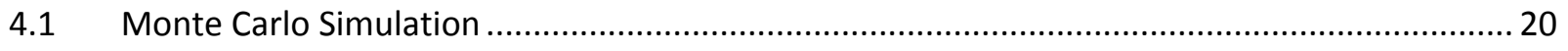

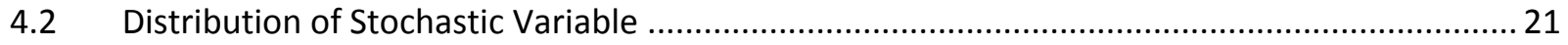

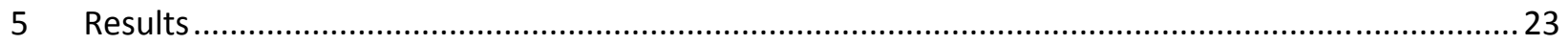

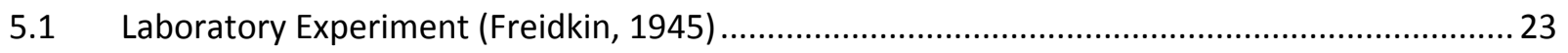

$5.2 \quad$ Simulated Results from Deterministic Model ........................................................................... 24

$5.3 \quad$ Simulated Results from Monte Carlo Simulation............................................................... 28

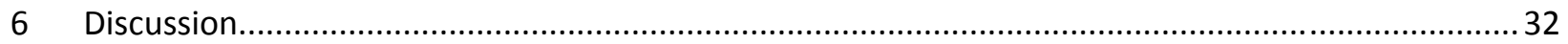

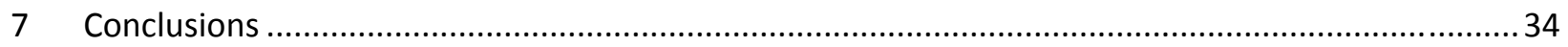

\section{Table of Figures}

Figure 1-1: Variables Used to Describe Geometry of a Meander (Khatsuria 2008) ................................10 Figure 1-2: Comparison of Venusian and Terrestrial Meander Geometries Illustrates that Relationships are Nearly of the Same Order of Magnitude (Komatsu and Baker 1994)

Figure 1-3: The Relatively Constant Ratio Between Meanders in Diverse Media is Suggestive (Marani 2002)

Figure 1-4: Meanders in Different Media Displays Remarkable Similarity of Scale (Leopold 1960) ......... 12

Figure 4-1: Uniform Distribution of Input Parameter .......................................................................... 22

Figure 4-2: Normal Distribution of Input Parameter through Box Muller Transformation ....................... 23

Figure 5-1: Results of Deterministic Models Johannesson and Parker (1989b) and Ikeda (1981) for 32-

hour Simulation of J.R. Friedkin (1945) Experimental Results...............................................................2 24

Figure 5-2: Excess Velocity Results of Flow Field Models Johannesson and Parker (1989b) and Ikeda (1981) for Initial Sine Generated Curve

Figure 5-3: Model Error for Distance from X-axis to Maximum Y-value for Each Bend Simulated for 32hour Friedkin (1945) Simulation 26 
Figure 5-4: Model Error for Deviation from the Mean Y-value for Each Bend Simulated for 32-hour Friedkin (1945) Simulation ......................................................................................................... 26

Figure 5-5: Model Error for Skew of Y-values for Each Bend Simulated for 32-hour Friedkin (1945)

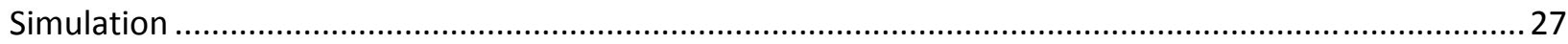

Figure 5-6: Model Results for Skew of Y-values for Each Bend Simulated for 32-hour Friedkin (1945)

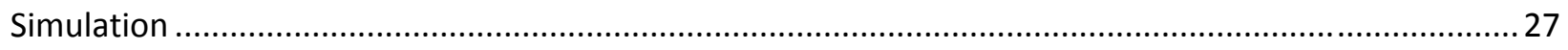

Figure 5-7: Interpolation from Curvilinear to Cartesian Coordinates....................................................... 28

Figure 5-8: 1000 Iterations of Ikeda et al. (1981) Model with 10\% Variability from 32-hour Calibrated

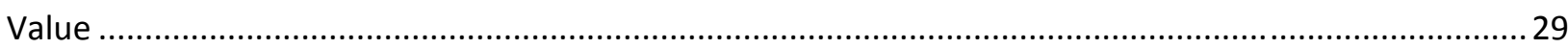

Figure 5-9: Results of Monte Carlo Analysis of 32-hour Calibrated Model with Ikeda (1981) Solution..... 29

Figure 5-10: Results of Monte Carlo Analysis of 32-hour Calibrated Model with Johannesson and Parker

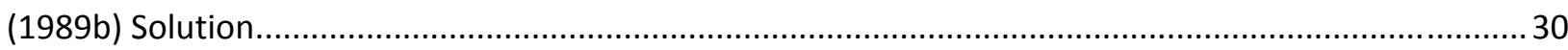

Figure 5-11: Comparison of Deterministic Model and Average Y-Max Value from Monte Carlo Simulation

Figure 5-12: Comparison of deterministic model and standard deviations of average y-value from

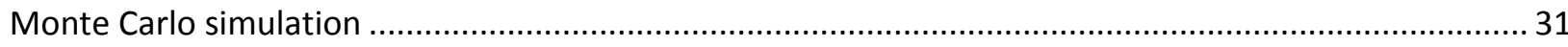

Figure 5-13: Comparison of Deterministic Model and Skewness of Average Y- Value from Monte Carlo

Simulation

Figure 5-14: Bends 4 and 5 of 32-hour Simulation with Results from Both Uniform and Normal

Distributions 32

Figure 6-1: Planform Evolution of Friedkin (1945) Experiments

\section{Table of Tables}

Table 4-1: Migration Rate and Erodibility Summary (Micheli and Kirchner, 2006) with Percent Error ....21

Table 5-1: Friedkin Initial Conditions for Simulation

Table 5-2: Mean Squared Error Values for Ikeda (1981) Model and Johannesson \& Parker (1989b)

Models 


\section{Introduction}

The interaction of hydraulics and sediment in curved open channels is not well understood. This research focused on this aspect of channel forming processes. River meander migration is one of the most intriguing and yet perplexing problems of open channel hydraulics. Only in the past few decades has significant progresses in understanding this phenomenon been accomplished; however, there is still no consensus regarding how to model this most basic behavior of natural rivers.

Motivation for the continued search for a mathematical model of this ubiquitous river planform includes:

- Our ability to explain complex natural phenomenon (Thompson 1876; Jefferson 1902; Leopold and Wolman, 1960)

- Issues associated with river ecological functions (Salo et al. 1986; Siem 2009, Moorhead 2008, Nakano, 2008)

- Protection of hydraulic structures, such as bridges and levees (US Army Corps of Engineers, 1981)

- Protection from erosion and flooding valuable agricultural and urban land uses (Wicker, 1983)

- The influence sinuosity may have on surface/groundwater interaction (Cardenas, 2009)

- Developing insight into oil reservoir formations created by ancient meandering rivers (Henriquez, et al.,1990; Swanson, 1993)

Research conducted in association with the Streambank Erosion Control Evaluation and Demonstration Act of 1974 (Sec 32, Public Law 32-251, submitted in December 1981), found that approximately 142,000 bank-miles of streams and waterways are in need of erosion protection. The cost to prevent or control this erosion by means of conventional bank protection methods was estimated to be in excess of $\$ 1$ billion annually. The cost estimate for the UpperMississippi River basin alone exceeded \$21 million annually.

Meanders are ubiquitous in open channels of over several orders of magnitude in size--from the smallest creek to the largest river. Meandering is not unique to rivers; it is also found in (Davies 1984, Thorne 1992):

- Capillary jets and rivulets running down roughened plates

- Human blood stream

- Water flowing over ice

- Ocean currents

- Planetary jet stream

- Channels carved by molten lava on the Moon 
- Sub-surface water flows on Mars.

There are important engineering applications to the fluvial geomorphological processes occurring at the river reach scale, such as infrastructure protection, flood protection, and more recently, kinetic hydropower. Through the damming of rivers and the conversion from pervious to impervious cover in our expanding metropolitan areas, we have dramatically altered the natural river systems in which biotic organisms have evolved along with the dynamic morphological equilibrium. Understanding the nature of these relationships and how they are responding to changing hydrologic, hydraulic, and sediment regimes is critical in our efforts to generate hydrokinetic power while protecting vital infrastructure and communities.

Meandering continues to be an enigma within the scientific community. Efforts to describe and understand this phenomenon date back to Leonardo de Vinci (Gyr, 2010). Although there is no unifying theory as to the development and maintenance of meanders, geomorphologists, fluid dynamicists, sedimentologists, mathematicians, and engineers all have their hypotheses. Much disagreement still exists concerning the classification and identification method of meanders; however, there are some generalities and descriptions that might help uncover the mechanisms behind meandering. These descriptions could aid our understanding of river planform evolution, as well as of ocean and atmospheric dynamics and planetary development.

Likely, the most fundamental problem in deriving some relation among different meander phenomena is their dynamic nature. Measuring the geometric and hydraulic variables associated with these planforms is but a snapshot in time. As these planforms are constantly changing, scientists use the relationships between variables in an attempt to find some constants. This strategy led to what is known as "Regime Theory" whose premise is that each fluvial system has an equilibrium state which it tends toward. Regime Theory was developed by the British during canal building in India. India was probably the largest Hydraulic Society prior to the water development in the southwestern United States and California, whose system of canals is one of the largest in the world. Their goal was to build a canal that would last, one in which sediment supply was commensurate with sediment transport, and one in which minimal aggregation or degradation would occur. Much collection and compilation of data led to a series of empirical relations which are still in use today, although there are many versions

The meandering phenomenon has had the most attention given to it by far in the context of alluvial rivers. Figure 1-1 shows the geometric variables used to describe meandering. Meandering alluvial rivers display an amazing amount of correlation between geometric variables over large spatial scales. 


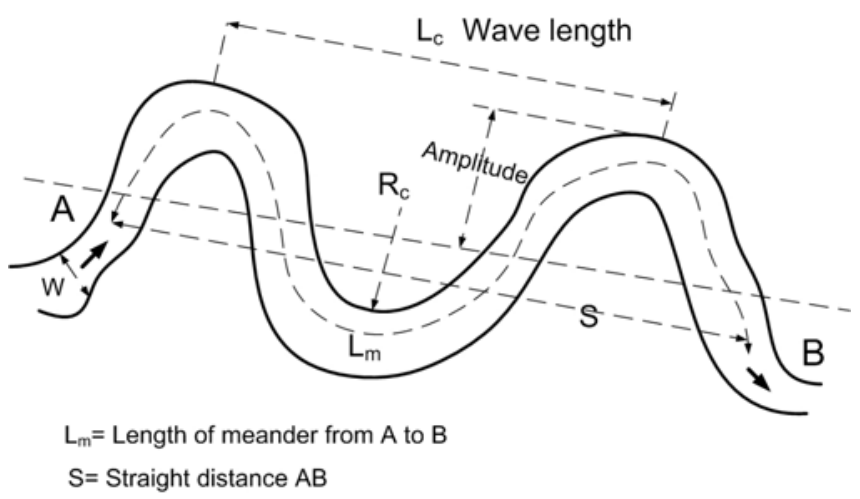

Geometric features of a meander

Figure 1-1: Variables Used to Describe Geometry of a Meander (Khatsuria 2008)

Some of those relations include:

$$
L_{c} \approx 7 W \text { to } 10 W(\text { Leopold 1960) }
$$

- $L_{c} \approx 6 W($ Gyr 2010)

- $L_{c} \approx 4.7 \overline{R_{C}}$ (Leopold 1960)

- Sinuosity $=\frac{L_{m}}{S} \approx 1.3-4$

In general, scientists use a power law relation to determine the relationships among geometric variables. This is done because data can be plotted on a log-log scale which minimizes differences between variables, especially at the value extremes. These relations take the form

$$
\operatorname{Var}_{1}=\operatorname{AVar}_{2}{ }^{B}
$$

Where $\operatorname{Var}_{1 \& 2}$ are geometric, variables and $A$ and $B$ are coefficients. Komatsu and Baker (1994) used these relations to show that Venusian channels have a similar relation to those found in terrestrial rivers, see Figure 1-2.

Where $\operatorname{Var}_{1 \& 2}$ are geometric variables and $A$ and $B$ are coefficients. Komatsu and Baker (1994) used these relations to show that Venusian channels have a similar relation to those found in terrestrial rivers, see Figure 1-3.

Meandering features can also be observed in tidal flats or coastal wetlands. Despite coming to the conclusion that, "in any real case of fluvial versus tidal patterns, differences are the norm rather than the exception once carefully examined," Marani (2002) found a significant correlation between channel width and meander length ( Figure 1-4). In addition, Marani (2002) found that tidal meander sinuosity varied from 1.3 to 2.2 , which is within the range found in fluvial meanders. Gustavson (1978) found that gravel bed rivers in south central Texas have a sinuosity of 1.3 . 


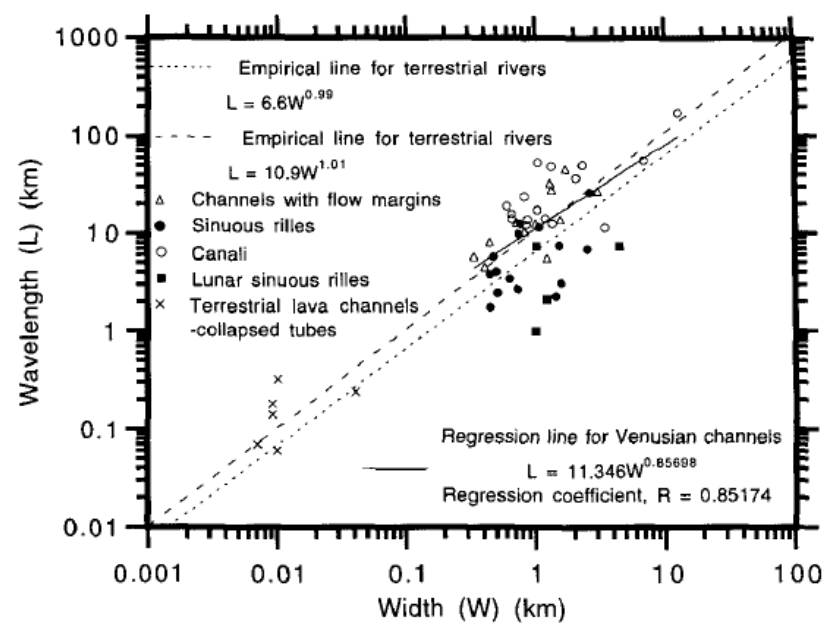

Figure 1-2: Comparison of Venusian and Terrestrial Meander Geometries Illustrates that Relationships are Nearly of the Same Order of Magnitude (Komatsu and Baker 1994)

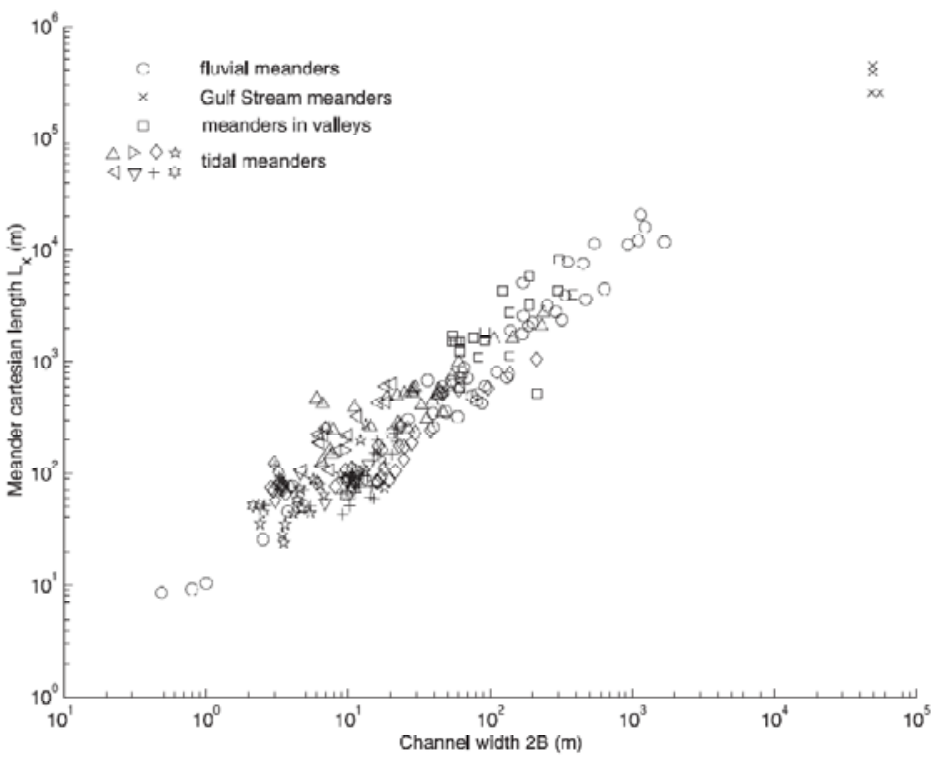

Figure 1-3: The Relatively Constant Ratio Between Meanders in Diverse Media is Suggestive (Marani 2002) 


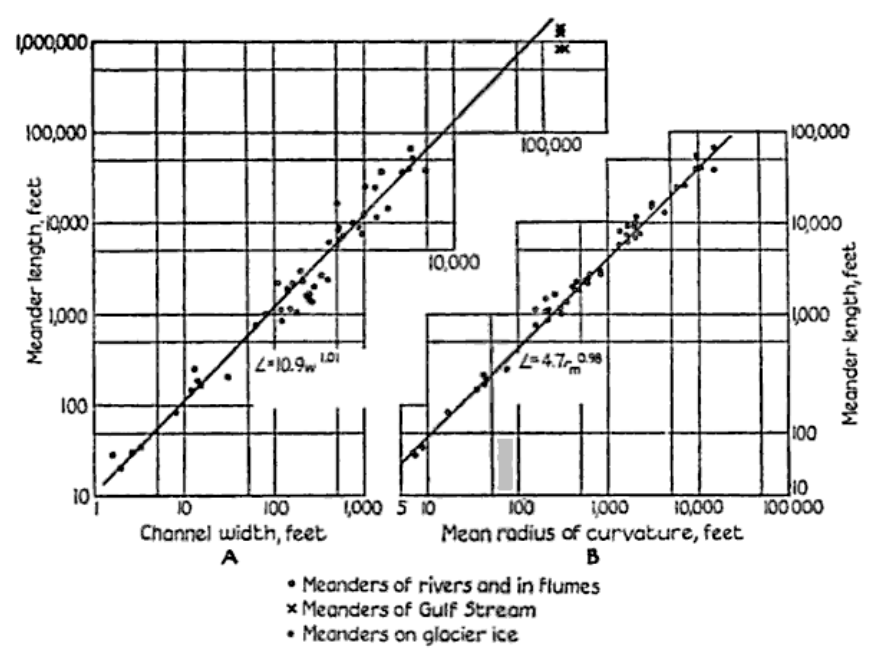

Figure 1-4: Meanders in Different Media Display Remarkable Similarity of Scale (Leopold 1960)

Leopold, et al. (1960), found that both the ratios of meander length-to-width and meander lengthto-mean radius of curvature are consistent among terrestrial rivers, experimental mobile bed flumes, the gulf stream, and glacier ice. There are several explanations as to how and why meanders form and why they share commonalities of scale.

\section{Causes of Meandering}

The cause of river meandering remains a subject of debate and discussion, as it has been for centuries. Leonardo de Vinci examined the phenomenon and observed that with an increasing length of flow path (i.e., sinuosity) the velocity decreases. Without the aid of mathematics, de Vinci came to the conclusion that flow is limited by extreme energy dissipation (Gyr 2010). Energy is clearly the central tool used to understand the meandering phenomenon; however, there remains debate about how to use our understanding of energy principles. Energy is not the only basis used to understand meandering, some logicians have proposed Coriolis forces, theories of random walks, and statistical descriptions based on the idea that the system is too complex to be described in mechanistic terms (Gyr 2010). The spatial similarity of scale across different media suggests there are some mechanisms controlling meandering.

Meandering is a paradox of physics, as the motion of a body in a potential field follows the path of the largest potential gradient, in other words, the river should flow straight down the valley. This is also known as the principle of least action. The reality that fluids in various media do not adhere to this rule suggests that friction forces must play a critical role in the origin of meanders, changing the potential field. Friction forces, such as shear stresses on the river bed and banks are inherent in the flow. Both suspended sediment and bed load transport are functions of the energy of the river. Due to the fact that meandering occurs in media where no sediment transport occurs has led some authors to conclude that sediment is not required for meandering, rather only necessary in a kinematic way to impose anisotropy on the bed. Parker (1976) suggests that beyond the inertial and gravitational potential and frictional effects, there is a 'third effect' 
provided by sediment in alluvial streams, by Coriolis acceleration in oceanic currents, by heat differences in glacial melt water, and by surface tension for Gorycki's streams.

Chang (1988) noted the importance of distinguishing that meandering is the effect, where the causes include the independent or controlling variables which are imposed upon the river channel. Chang (1988) also states that determination of the dependent and independent variables is subject to the time scale under consideration; however, he left out the importance of spatial scale when discussing these variables. For example, the minimum energy principle elaborated by Huang (2004) suggests that the driving mechanism for channel cross-sectional shape and river planform is the ratio of the valley slope to that of the minimum friction slope of the river and sediment regime. This principle, shared by many explanations of meandering, is clearly responsible for a river's tendency to meander and braid and has been used successfully to distinguish regimes that lead to straight, meandering, and braided streams. This reasoning along with stability theory can also be used to show that there exists an optimal value of the scale among a river system's independent variables.

These analyses led Braudricka et al. (2009) to hypothesize that in addition to hydraulic conditions that support meandering, the necessary conditions to obtain successful experimental meandering were:

- Bank strength greater than that due to deposited bedload (to slow outer bank erosion rate),

- The addition of suspended load (to both settle out in the chutes, reducing the tendency for a low sinuosity cutoff, and to become deposited on the bar top, raising the surface to floodplain level), and

- Periodic overbank flow (to raise the depositional surface of the point bar and to disperse suspended sediment into nearby low areas).

The results of their experiments strongly supported the first two hypotheses, and found that variable peaks were not required to maintain meanders. These results supported the hypothesis that the overall energy gradient is an important variable in determining river geometry scale.

Discussions on the origin of river meandering do not take into account spatial scale. Scientists focusing on the energy gradient between the valley and river slopes and those examining the role of helical flow are actually investigating the same phenomenon on two different scales. The 'third effect' proposed by Parker (1976) explains how ideal non-frictional flow develops helical cells that drive anisotropy in flow and the media within which it runs. Arguments, such as the minimum energy principle, explain how those flow anisotropies organize into a macroform controlling dependent variables of meander wavelength, radius of curvature, stream width and depth, and their ratios. I believe there is a false controversy and that in fact both arguments are correct and dependent on the scale in which the conundrum is approached.

Scientists have approached these relationships on various spatial and temporal scales. Modeling efforts have grown in sophistication with the advent of more powerful computation abilities, the availability of additional data sets from new sources, and methods such as satellite imagery and the Acoustic Doppler Current Profiler. Scientists build sophisticated numerical models to represent natural phenomenon; however, they are then required to make many simplifications and assumptions in order to be able to close these systems of equations and get an answer to the problem. There are two main strategies used to deal with this problem: One strategy is to 
implement stochastic simulations of those numerical models, wherein an effort is made to build into the model the variability and error associated with that particular numerical model. This is often accomplished through representing one or multiple model parameters with random numbers rather than a single number. Another method to resolve the gap between model results and observed data is to maintain as much of the complexity of the model as possible. This is becoming increasingly possible with the increase in computational power. Rather than use various simplifications and mathematical procedures to solve these systems of equations, various numerical schemes have been developed. While these numerical schemes allow for 3-D simulations of the velocity profiles, they are very computationally intensive and make simulations of long river reaches and long time scales impractical.

\section{Bend Hydraulics and Channel Adjustment}

Although the precise cause of meandering remains unknown, the propensity of fluids to meander indicates that this behavior is inherent to shear flows and cannot be attributed solely to nonuniformity of sediment transport or bank erosion. In streams, it seems that meandering is caused from the time averaged flow field from coherent flow structures tied to the channel cross section (Ashworth, 1996). The eddies created induce a sinuous path of the maximum velocity pathline that is strengthened by positive feedback from curvature and Prandtl's first kind of secondary currents (Brathurst, 1979). With a movable bed, this asymmetry in velocity and boundary shear stress results in the generation of pools, riffles, and alternate bars (Smith, 1987). Provided erodible banks, the sinuous pathline initiates a matching pattern in the bank lines that define the initiation of channel meandering (Friedkin, 1945). Most authors agree that the threshold for meandering is defined as a sinuosity, the quotient of channel length by down valley length, of 1.3 to 1.5 (Leopold, 1964).

Efforts to quantify and predict meander processes began with the recognition of the visual similarity, regardless of scale, due to certain geometric proportions common to all river; such as, a nearly constant ratio of radius of curvature to meander length and radius of curvature to channel width (Leopold and Wolman, 1960). With these observations and a recognition of the superposition of many diverse processes, scientists developed statistical models based on heuristic arguments (Langbein and Leopold, 1966; Surkan and van Kan, 1969; and Ferguson, 1977, 1983). These models are based on the assumption that the geometry of a meander is a random walk whose most frequent form minimizes the changes in direction through adjustments in depth, velocity, and slope to decrease the variance in shear and friction forces in a meander relative to a comparable straight reach. While these models generate meandering patterns on large scales, they cannot be used to predict the meander evolution process.

Flow around bends is complex, as was recognized over a century ago (Thompson, 1876). Flow through a bend is subject not only to gravitational and frictional forces, but also to a centrifugal force acting outward on the water. This centrifugal force is proportional to the flow velocity squared, and due to the parabolic vertical velocity distribution, the centrifugal force also varies with depth. The outward directed centrifugal force causes a water and momentum flux toward the outer bank, resulting in a buildup of water. The raising of the free surface is referred to as "super-elevation" (Markham, 1990) that causes an inward acting pressure gradient force, which has a uniform magnitude through the flow depth. At the water surface the centrifugal force exceeds the pressure gradient and at the bed the pressure gradient exceeds the centrifugal force, 
resulting in a "secondary circulation" in the transverse plane (Darby, 1993). Numerous studies have identified that the velocity maxima shifts from the inner to outer banks around a bend in both laboratory settings (Hooke, 1975; Kikkawa, 1976; Chen, 1983) and in natural channels (Bridge, 1977, 1982; Brathurst, 1979; and Dietrich, 1983). In addition, Brathurst (1979) found that sheer stress peaks occurred beneath the velocity maxima, at the junction of outer bank and main secondary cell. While there is still some debate about the importance of secondary flow in the near bank erosion mechanisms (Thorne, 1978, LaPointe, 1986; Kitidanis, 1984), it is clear that secondary flows do influence primary flows near the bank and may also influence fluid sheer stresses on the side wall.

- Approaches based on the fundamental laws of physics to solve the distribution of velocity and sediment as it relates to bed topography began with the pioneering work of Dutch scientist L. Van Bendegom (1947). The simplest case is that of uniform curvature for fully developed flow. Rozovskii (1957) was the first to obtain an analytical solution for the secondary flow in channel bends. In order to facilitate the solution of the mathematical model, Rozovskii introduced several simplifications and approximations including:

- The water surface boundary is considered a rigid impermeable and shear stress free plate, which introduces only small error so long as the difference between local and average water surfaces are small and requires that the Froude number and ratio of water depth to radius of curvature both be small (Olsen, 1987)

- By neglecting wall effects, friction terms only vary as a function of depth. This simplification implies that all lateral exchanges of momentum due to friction in the fluid are neglected, limiting the validity of the model to the central region of wide channels (Darby, 1993).

- A hydrostatic pressure distribution, which also causes problems near the bank where there are significant dynamic vertical vortices.

In order to close the solution set, Rozovskii (1957) was also required to make assumptions about:

- The eddy viscosity distribution, and

- A number of boundary conditions

While this approach gives acceptable results in the central region of the bend, solutions near the bank zones are invalid.

Many other bend models were proposed from the time of Rozovskii's pioneering work, in an effort to tie flow in bends to the bed topography. The next significant improvement in these efforts was accomplished by Engelund (1974), who claimed that the vertical velocity profile could be best described in natural rivers by the velocity defect law. Using this assumption he was able to first approximate two-dimensional bend flow. He then included some second order calculations to account for the effect of radial variations of depth and velocity on the flow field (Markham, 1990).

Much work was also done by Bridge et al. to refine this method to model the flow and bed topography in river bends (Bridge, 1977, 1982, 1984; Bridge \& Jarvis, 1982). Along with the restrictions associated with Rozovskii's solution, the Enguland-Bridge approach treats the 
convective acceleration terms as second order. Both field (Dietrich \& Smith, 1983) and laboratory data (Yen \& Yen, 1971) indicate that convective acceleration terms should be first order. Scaling arguments corroborate these findings (Smith and McLean, 1984; Nelson, 1988). Dietrich and Smith (1983) found "substantial topographic induced alteration in the cross stream flow pattern relative to that for analogous constant bottom cases." A high velocity filament upstream of the bend travels over the shoal directing it toward the pool, where first the decrease in the transverse slope and second the dominance of the vertically averaged centrifugal force result in the significance of the convective acceleration term (Dietrich \& Smith, 1983), not represented in the Engelund-Bridge models.

Bank erosion is a natural adjustment mechanism of channels of dynamic non-equilibrium. Alluvial channels adjust themselves to reach regime conditions not only through the degradation and aggradation of the river bed, but also through width adjustment and planform evolution. The rate of bank erosion may depend on a variety of parameters including soil properties, the frequency of freeze-thaw, the stratigraphy of the bank, the type and density of vegetation, and sediment grain size at the toe of the bank (Micheli and Kirchner, 2002). Bank erosion caused by hydraulic forces acting on bank surface, and the failure of banks due to geotechnical instability of the bank are the most commonly observed bank erosion phenomena in nature. In general, bank erosion of non-cohesive materials usually proceeds through the following sequence:

1. Bed scouring that steepens the side bank

2. Bank collapse due to instability of the scoured bank

3. Deposition of the collapsed bank materials at the front of the bank

4. Transportation of the deposited material downstream (Duan, 2005; Darby et al. 2002).

Stages one and two of the sequence are due to fluvial entrainment and geotechnical instability, and stages three and four depend on the sediment transport capacity near the banks.

Several mechanisms for mass failure have been observed including planar, rotational, cantilever, piping, and sapping type failures (Osman and Thorne, 1988; Darby and Thorne, 1996). These processes have been of interest to geotechnical engineers with regard to the design of artificial slopes and embankments. Osman and Thorne (1988) developed a theoretical model to calculate the bank erosion of steep banks of cohesive materials, which researchers modified to include the location and depth of tension cracks (Darby and Thorne, 1994), pore-water and hydrostatic confining pressure terms (Darby and Thorne, 1996), soil moisture content, and stochastic property of bank failure (Duan, 2005). These solutions require the calibration of soil erodibility index and other parameters as well as considerable field data to describe geotechnical properties of the banks. This physically based method has been applied to simulate bank erosion processes of laboratory cases (Darby et al., 2002; Duan and Julien, 2005), but is limited for long-term simulation of natural rivers due to data constraints. Therefore, this study focuses on the linear bank erosion model (Ikeda et al., 1981) which has been reported to be successful in simulating the long-term evolution of meanders of large scale rivers.

\subsection{Modeling Meander Evolution}

Regarding the rate of bank erosion, the approach by Ikeda et al. (1981) was among the pioneering works addressing bank erosion when studying alluvial channel processes. In their approach, the bank erosion rate $(\zeta)$, is linearly related to the excess near-bank velocity $\left(u_{b}^{\prime}\right)$, 
which is the difference between depth-averaged velocity at the outer bank and cross-sectional mean velocity, through the linear erodibility coefficient $(E)$.

$$
\zeta=E u_{b}^{\prime}
$$

According to Ikeda's linear bank erosion equation, the bank retreats if the excess near-bank velocity is greater than zero; otherwise, the bank advances. Ikeda et al.'s (1981) solution to the velocity excess is based on the depth averaged Navier Stokes equations for shallow water flow in curvilinear coordinates, making the traditional assumptions of steady flow in a constant width channel, with small ratios of width to centerline radius of curvature. Ikeda et al. (1981) closed the system of equations using the previous analyses (Enguland, 1974; Ikeda, 1975; Kikkawa et al. 1976; Zimmerman and Kennedy, 1978) where a "scour factor," A, is used to define a relationship between the transverse bed slope and water surface slope. Engelund (1974) suggested a value of 4.0. The theories of Kikkawa et al. (1976) and Zimmerman and Kennedy (1978) showed that this parameter should increase with the streamwise velocity. The authors chose to use an average value based on Suga's (1963) analysis of 45 river bends in 10 alluvial rivers in Japan, suggesting a value of 2.89. Using the above assumptions and solving for velocity at the outer bank using the $1^{\text {st }}$ order approximation of Navier Stokes equation in curvilinear coordinate as follows,

$$
U \frac{\partial u_{b}^{\prime}}{\partial s}+2 \frac{U}{H} C_{f} u_{b}^{\prime}=b\left[-U^{2} \frac{\partial \mathcal{C}}{\partial s}+C_{f} \mathcal{C}\left(\frac{U^{4}}{g H^{2}}+A \frac{U^{2}}{H}\right)\right]
$$

where $U$ is the depth-averaged velocity for the stream reach, $s$ is the streamwise distance, $H$ is the reach-averaged depth, $C_{f}$ is the friction factor, $b$ is the reach averaged half-width, $\mathcal{C}$ is the local curvature, $g$ is the gravitational constant of acceleration, and $A$ is the scour factor. This solution of near-bank excessive velocity was then used to predict bank erosion or deposition through the assumption that bank erosion/deposition rate is linearly proportional to the near bank velocity, equation 1 .

This approach was then used intensively to predict bank erosion (Parker, 1982; Johannesson, 1985) and was foreseen by Hasegawa and Ito (1987). However, several authors (Johannesson, 1985) corrected the Ikeda et al. (1981) model when discovering that it did not account properly for the streamwise pressure gradient. This term gives rise to the irrotational vortex and thus results in higher velocities over the inside bank than the outside bank when applied to a developed bend flow over a nonerodible bed that is horizontal in the transverse direction (Johannesson and Parker, 1989b). This result contradicts those findings by Kikkawa (1976), which was also confirmed by the observations of Parker (1982) and Johannesson (1985). As a consequence, when applying the Ikeda et al. (1981) model, significant calibrations were required in order to obtain results matching field observations (Johannesson and Parker, 1989b).

Johannesson and Parker (1989b) developed a bend flow model based on the fact that the convective transport of primary flow momentum by the secondary flow results in a significant outward redistribution of primary flow velocity. Although the importance of this phenomenon was recognized by several researchers, the term was neglected by Ikeda et al. (1981). While a phase shift between the secondary current strength and the local centerline channel curvature was identified as an effect of the fluid inertia by Gottlieb (1976) and Kitanidis and Kennedy (1984), it was Ikeda and Nishimura (1986) who retained the fluid inertia in the equation governing secondary flow and included an unverified approximation assuming the phase shift is independent of depth. Johannesson and Parker (1989a) derived a solution to the primary and 
secondary flows through the use of Engelund's (1974) slip velocity method, a logarithmic velocity profile, and the condition of vanishing shear stress at the water surface. The solution is then generalized for a sinuous channel, where an expansion for small curvature was implemented. By retaining only the linear terms and dropping the second order, $0\left(\varepsilon^{2}\right)$, terms, a solution could be reached. Through their analysis, Johannesson and Parker (1989a) determined that this methodology, when applied to the solutions developed by Ikeda and Nishimura (1986), yielded velocity distributions that better matched the observed data due to the central assumption that the secondary flow maintains the same vertical profile as that of the developed bend flow, with changes only in magnitude and phase. Therefore, the essential contribution of Johannesson and Parker (1989b) can be summarized in the following relation

$$
r \frac{d u_{b}^{\prime}}{d \theta}+2 u_{b}^{\prime}=-r \chi_{20} \frac{d \sigma}{d \theta}+\left(F^{2} \chi_{20}-1\right) \sigma+\left(A+A_{s}\right) \sigma_{s}
$$

where $r$ is the rescaled wavenumber and is found as the original wavenumber, $\mathrm{k}$, divided by the scaling factor $\epsilon=C_{f} b / H, \theta$ is the streamwise downstream angle relative to the $\mathrm{x}$-axis, $\chi_{20}$ is the redistribution effect of the secondary flow, $\sigma$ denotes an order-one dimensionless curvature, $A_{s}$ is the result of integrating across the stream width the normalized vertically averaged lateral transport of downstream momentum by the secondary flow, $\sigma_{s}$ quantifies the strength of and the phase shift in the secondary flow due to changing curvature in a sinuous channel and satisfies the relation

$$
r \frac{d \sigma_{s}}{d \phi}+\delta \sigma_{s}=\delta \sigma
$$

where $\delta$ comes from the relation for the secondary flow strength. The final results (Johannesson and Parker, 1989b) can be used as the $1^{\text {st }}$ order analytical solution for the velocity excess in meandering streams of any arbitrary curvature.

The erosion coefficient is required to account for variations in the properties of bank material, such as cohesion and vegetation. The bank erosion coefficient employed by Crosato (1990) included the effect of both fluvial erosion and bank failure. The universal bank erosion coefficient by Hasegawa (1989) relates the bank erosion rate to the cross-sectional mean velocity, which was validated using data from alluvial channels in Japan. A detailed study of bank migration rates and velocity profiles in a southeastern Pennsylvania stream by Pizzuto and Meckelnberg (1989) suggests that the linear bank erosion equation is suitable for streams with cohesive and relatively uniform bank materials. Hasegawa (1989) used a solution to the sediment continuity equation at a cross section and found that meandering migration was a linear function of the velocity excess. While all authors agree the bank erosion coefficient is related to geophysical properties of the bank (Hasegawa, 1989; Wallick et al., 2006) and effects of vegetation (Pizzuto and Meckelenberg, 1989; Micheli et al., 2004), among other hydrodynamic, planform, and sediment characteristics, only recently have geotechnical properties been tested in an effort to correlate those properties with the linear erosion coefficient by taking soil samples and submitting them to lab scour tests (Constantine, 2009).

Nearly all studies employing Eq. 1 have used the historical record to calibrate a constant value of erosion coefficient, E, and then used it to predict future meander propagation (e.g., Larsen and Greco, 2002). Parameters for determining bank erosion coefficients including bank soil properties, channel geometries, and flow fields vary along the stream. Bank soils and bed materials in particular are heterogeneous. A constant bank erosion coefficient used for an entire 
study reach is inappropriate. All of the parameters, along with the random spatial variations in bank erosion rates, led Hooke (1979) and Pizzuto and Meckelnberg (1989) to conclude that a constant value of bank erosion coefficient in equation 1 may not adequately represent either systematic or random variations of soil properties, channel geometries, or flow properties that influence the rate of bank erosion. The bank erosion coefficient should be a stochastic variable with a mean value based on the averaged values of soil, cohesiveness, vegetation density, geometry, and flow properties.

To examine the accuracy of various methods for meander evolution simulation, an approach to compare models' accuracies must be proposed. River planforms take complex geometries which are best represented in body-fitted curvilinear coordinates. Computer simulation pre- and postprocessing involves the conversion from the curvilinear to the Cartesian coordinates and vice versa. Traditionally, model errors are the differences of the simulated and observed data at discrete time intervals. The field data to verify meandering models' results are series of meandering planforms which cannot be assessed by the traditional method. Unique metrics and algorithms must be developed to determine which simulated planform is the best representation of the observed one.

Therefore, the purpose of this study is twofold: first to examine the existing method for bank erosion calculations and to develop a method for quantifying errors of modeling results, and second, to represent the uncertainty associated with the linear bank erosion coefficient through a Monte Carlo simulation.

\section{Computational Model}

This study developed two one dimensional numerical models for simulating bank erosion and the consequent meandering planform evolution. The flow field was based on the $1^{\text {st }}$ order solution of Navier Stokes Equations in the curvilinear coordinate derived by Ikeda et al. (1981) and Johannesson and Parker (1989b). The Ikeda et al. (1981) model is based on their solution for velocity excess, $u_{b}^{\prime}$. This model adopts the explicit upstream difference scheme in Eq.4 to integrate Eq.2 (Sun 1996),

$$
\left.\frac{d u_{b}^{\prime}}{d s}\right|_{i}=\frac{u_{b_{i}}^{\prime}-u_{b_{i-1}}^{\prime}}{\Delta s}
$$

where $\Delta s$ is the streamwise distance between nodes, subscription i denotes the node number. The recursive equation is written as,

$$
u_{b_{i}}^{\prime}=\frac{b}{U / \Delta s_{i}+2(U / H) C_{f}}\left[-\left.U^{2} \frac{\partial \mathcal{C}}{\partial s}\right|_{i}+C_{f} \mathcal{C}_{i}\left(\frac{U^{4}}{g H^{2}}+A \frac{U^{2}}{H}\right)+\frac{U}{\Delta s_{i}} \frac{u_{b_{i-1}}^{\prime}}{b}\right]
$$

is the friction factor, The variables are defined in Eq.2. The friction factor is an expression of the shear stress, and comes from the solution of the s-momentum equation after a linear perturbation analysis and Taylor expansion to the zero-order, where shear stress is approximated as $\tau_{s}=$ $\rho C_{f} U^{2}$, yielding

$$
C_{f}=g H I / U^{2}
$$

For an initial sine generated sinuous channel, the downstream angle can be determined by 


$$
\theta=\theta_{0} \cos (k s)
$$

where $\theta_{0}$ is the initial angle, $k$ is the wavenumber defined as $2 \pi / \lambda$, where $\lambda$ is the wavelength, and $\mathrm{s}$ is the distance downstream. As the river planform takes an arbitrary form where subsequent nodes may be in any direction, an algorithm using trigonometric identities is required to find the downstream angle. Curvature of the centerline in this model is calculated as the ratio of change in downstream centerline angle and the $\mathrm{x}$-axis over a unit streamwise length. In addition, after each time interval, nodes along the streamline were redistributed to keep equal spacing as channel evolution occurs. The spacing of nodes was maintained always equal to the channel width so extra nodes were added as the meandering bend lengthens.

Johannesson and Parker (1989b) made some significant changes to the model proposed by Ikeda et al. (1981). In this model, the analytical solution found to Eq.3 was used with the substitutions suggested, $\phi=k s$ and $r=k H / C_{f} b^{2}$, setting initial conditions to zero, and estimating $\sigma_{s}=\sigma=$ $\mathcal{C} b$ which gives,

$$
\begin{gathered}
u_{b}^{\prime}=-\chi_{20} \mathcal{C} b+\frac{C_{f} b^{2}}{H}\left[\chi_{20}\left(\frac{U^{2}}{g H}+2\right)-1\right] e^{-\frac{-2 C_{f} b^{2} s}{H}} \int_{0}^{s} \mathcal{C}\left(s^{\prime}\right) e^{-\frac{2 C_{f} b^{2} s}{H}} d s^{\prime}+\frac{C_{f} b^{2}}{H}(A+ \\
\left.A_{s}\right) e^{-\frac{-2 C_{f} b^{2} s}{H}} \int_{0}^{s} \mathcal{C}\left(s^{\prime}\right) e^{-\frac{2 C_{f} b^{2} s}{H}} d s^{\prime}
\end{gathered}
$$

where $r$ is the rescaled wavenumber and is found as the original wavenumber, $\mathrm{k}$, divided by the scaling factor $\epsilon=C_{f} b / H, \theta$ is the streamwise downstream angle relative to the x-axis, $\chi_{20}$ is the redistribution effect of the secondary flow represented as

$$
\chi_{20}=\frac{1}{\chi_{1}^{3}}\left(\chi^{3}+\chi^{2}+\frac{2}{5} \chi+\frac{2}{35}\right)
$$

where $\chi=\chi_{1}-\frac{1}{3}$, and $\chi_{1}=\frac{0.077}{\sqrt{C_{f}}}, \sigma$ denotes an order-one dimensionless curvature and can be approximated as $\sigma=\mathcal{C b}, A_{s}$ is the result of integrating across the stream width the normalized vertically averaged lateral transport of downstream momentum by the secondary flow yielding the relation

$$
A_{s}=181\left(\frac{H}{b}\right)^{2} \frac{1}{\chi_{1}}\left(2 \chi^{2}+\frac{4}{5} \chi+\frac{1}{15}\right)
$$

which is of the same order as the scour factor, A.

This study used both the Ikeda et al. (1981) and Johannesson and Parker (1989b) solutions for the excess velocity, then Eq. 1 was used for solving the bank erosion rate with an assumption of either a constant or a stochastic erosion coefficient .

\subsection{Monte Carlo Simulation}

The bank erosion coefficient is treated as a stochastic variable. In order to determine the appropriate range of values, Hasegawa's (1989) solution to the sediment continuity at a representative elementary volume was used. Hasegawa found that bank erosion could be estimated through the product of the velocity excess and a constant term, equivalent to the bank erosion coefficient, as follows

$$
\zeta=\frac{3 q_{s_{0}} \operatorname{Ttan}\left(\theta_{k}\right) \phi_{*}}{(1-\lambda) H_{0} U_{0}} u_{b}^{\prime}
$$


where $q_{s_{0}}$ is the average bed load transport, $T=\sqrt{\tau_{*_{c}} / \mu_{s} \mu_{k} \tau_{*_{0}}}$, where $\mu_{s}$ and $\mu_{k}$ are the static and dynamic Coulomb coefficient respectively, $\theta_{k}$ is the transverse slope, $\phi_{*}=\tau_{*_{0}} / \tau_{*_{0}}-\tau_{*_{c}}, \lambda$ is the porosity, $H_{0}$ is the average depth, and $U_{0}$ is the average velocity. In Eq. $12, T, H_{0}, U_{0}$, and $\theta_{k}$ varied with instantaneous flow turbulence properties therefore are random variables, while $\lambda$ is the porosity and its spatial distribution depends on the local soil moisture content, which is a random variable. Several authors have noted the uncertainty associated the bank erosion rate (Wallick et al., 2006; Pizzuto and Mecklenberg, 1989). Wallick et al. (2006) found that the errors in their bank erosion coefficient estimates due to river planform variations to be in the range of $\pm 10 \%$ to $\pm 15 \%$. Micheli and Kirchner (2006) used the historical data of bank erosion rate and Eq. 1 to back-calculate bank erodibility coefficients for both wet and dry meadows along the south fork of the Kern River. The back-calculated coefficients varied spatially and temporally. Table 4-1 summarizes the percent error in their estimates.

\section{Table 4-1: Migration Rate and Erodibility Summary (Micheli and Kirchner, 2006) with Percent Error}

$\begin{array}{lll}\text { Migration Rate }\left(\mathrm{m} \mathrm{a}^{-1}\right) & \text { Standard Error } & \text { Percent Error } \\ 1.3 & 0.4 & 30.77 \% \\ 1.5 & 0.1 & 6.67 \% \\ 0.23 & 0.02 & 8.70 \% \\ 0.25 & 0.01 & 4.00 \%\end{array}$

\begin{tabular}{llll}
\hline Erodibility & $10^{-7}$ & & \\
\hline 0.58 & & 0.02 & $3.45 \%$ \\
0.64 & 0.03 & $4.69 \%$ \\
3.7 & 0.5 & $13.51 \%$ \\
8.4 & 0.7 & $8.33 \%$ \\
& & & Average Percent Error \\
& & & $10.01 \%$
\end{tabular}

The results showed an average error of approximately $10 \%$. Therefore, based on these field data (Wallick et al., 2006; Micheli and Kirchner, 2002) the bank erosion coefficient was determined to vary by about $10 \%$ from its mean value at a given river reach. Larger variations are expected in a long river reach of complex geometry, where bank soil properties are stratified, areas where vegetation may play a large role in streambank migration, and smaller variations are expected for the laboratory experimental channel.

\subsection{Distribution of Stochastic Variable}

The instantaneous bed shear stress in Eq. 12 can be either normally or log-normally distributed (Lopez and Garcia, 1999; Cheng and Law, 2003). The Cheng and Law (2003) experimental study indicated that the log-normal distribution converged to a normal distribution when the relative intensity of bed shear stress, denoted as the ratio between the deviation and mean of bed shear stress, is small. In shallow open channel flow, the turbulence intensity is much smaller than the mean shear stress (Duan and Barkdoll, 2008). Therefore, this study adopted the assumption that bed shear stress satisfies a standard normal distribution. The porosity in Eq.12 could satisfy 
either the uniform distribution or the normal distribution. With those distributions of individual variables, the study assumed the probability density function of bank erosion coefficient satisfies either the normal distribution or the uniform distribution as shown in Figure 4-1.

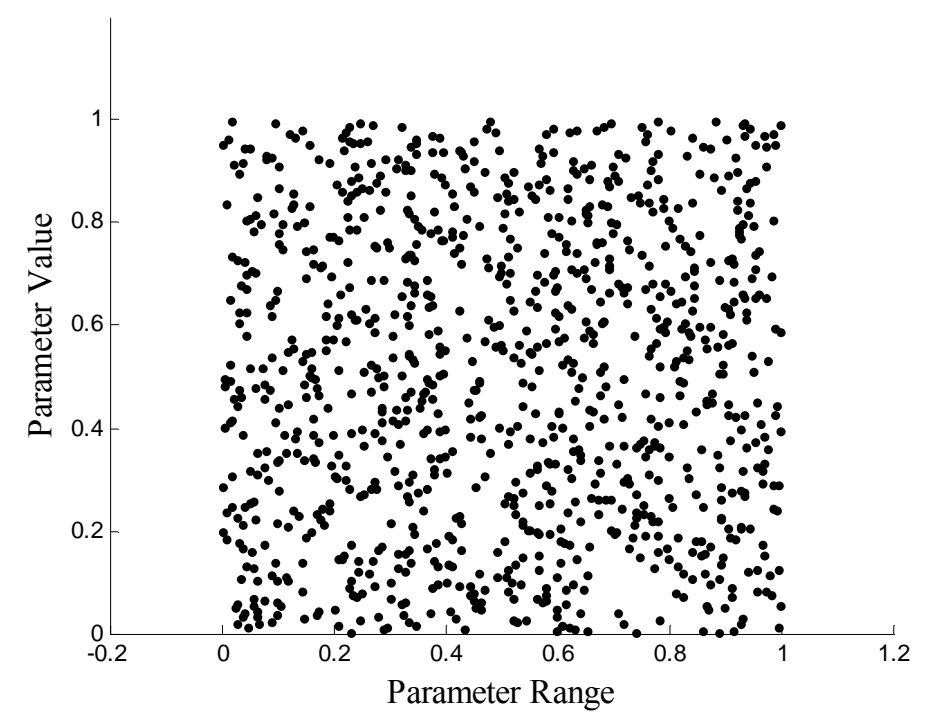

Figure 4-1: Uniform Distribution of Input Parameter

The bank erosion coefficient was first determined by calibrating the model using the observed data. The instantaneous bank erosion coefficient at each bank was obtained from a random distribution function, which is based on the intrinsic function that produces random numbers between zero and one assuming a uniform or normal distribution. If assuming the normal distribution of $E$ and employing the Box and Muller (1958) transformation, the PDF function of $E$ is shown in Figure 4-2. 


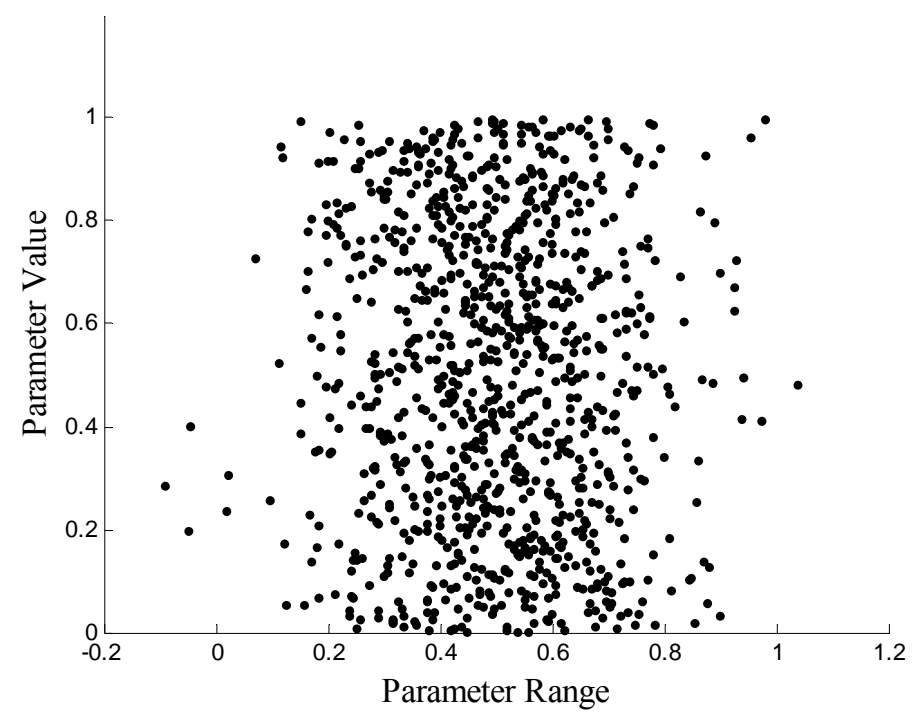

Figure 4-2: Normal distribution of input parameter through Box and Muller transformation

This study simulated one thousand iterations for each distribution so as to determine the statistical properties of the results including the 95 percent confidence interval and the average stream centerline position.

\section{Results}

\subsection{Laboratory Experiment (Freidkin, 1945)}

A comprehensive laboratory study of river meandering was conducted at the Waterway Experiment Station, Army Corps of Engineers by J.F. Friedkin (1945). Among dozens of experimental runs, one began with a sine-generated initial channel of trapezoidal cross sections, and uniform bed and banks, was run over several hours with a constant flow condition (see Plate 23 therein in Fredkin 1945). The constant discharge is $0.21 \mathrm{l} / \mathrm{s}$, and the channel width is $0.40 \mathrm{~m}$ with a side slope of $2: 1$. The total channel length is $12 \mathrm{~m}$. The experimental data including flow velocity, channel slope, Friction Factor, Froude number are summarized in Table 5-1. These experimental data are a unique opportunity to measure model errors with respect to the axial symmetry of the initial streamline. 


\section{Table 5-1: Friedkin Initial Conditions for Simulation}

\section{Parameter}

Initial Angle (degrees)

Wavelength $(\mathrm{m})$

Half bottom width (m)

Side Slope $(\mathrm{H}: \mathrm{V})$

Number of Wavelengths

Stream Flow $\left(\mathrm{m}^{3} / \mathrm{s}\right)$

Stream Height (m)

Scour Factor (A)

Simulation Duration (hrs)

Erodibility Coefficient, E

Average Velocity $(\mathrm{m} / \mathrm{s})$

Froude Number

Friction Factor

Bed Slope
Value

30.0

6.4008

0.3048

1.0

5.0

1.0

0.09

2.89

32

$2.2 \times 10^{-4}$ (calibrated value)

0.508

0.536

$2.6064 \times 10^{-2}$

$7.5 \times 10-3$

\subsection{Simulated Results from Deterministic Model}

The solutions of velocity excess from both models (Ikeda et al. 1981 and Johannesson and Parker, 1989b) in conjunction with Eq.1 were used to simulate the 32-hour experimental run. The simulated results were compared with the experimental measurements as shown in Figure $5-1$

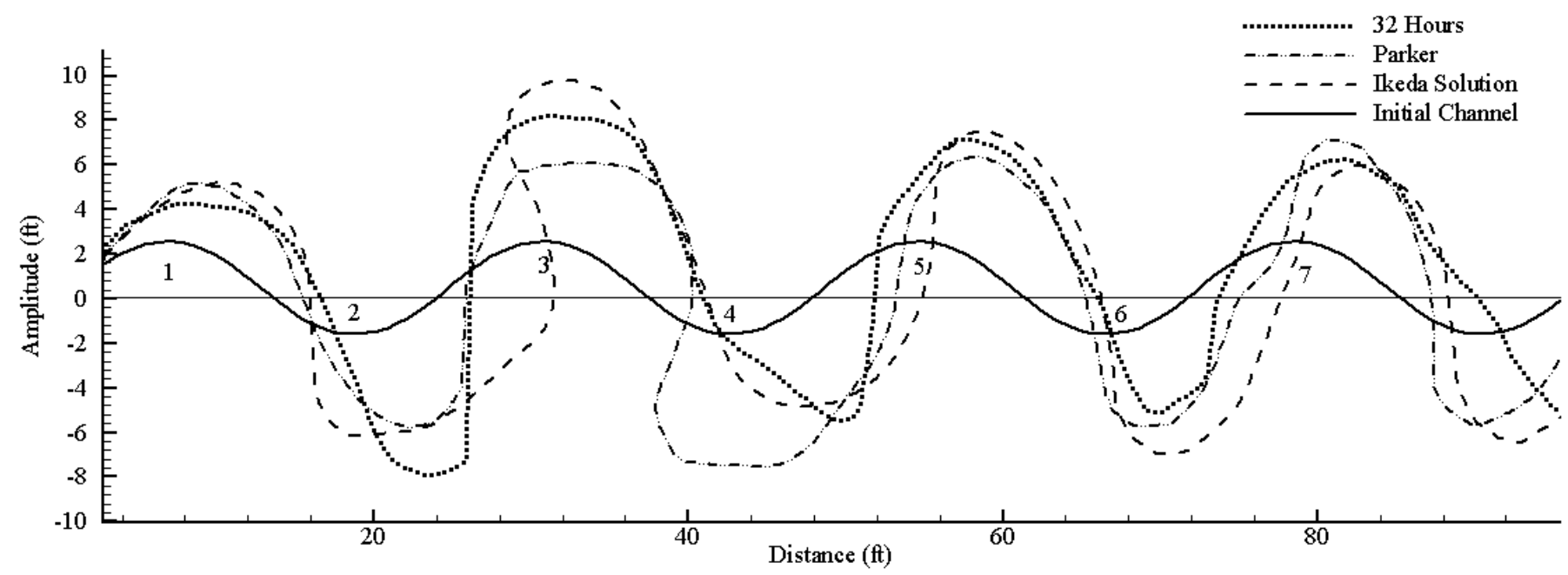

Figure 5-1: Results of Deterministic Models Johannesson and Parker (1989b) and Ikeda (1981) for 32-hour Simulation of J.R. Friedkin (1945) Experimental Results

In the deterministic solution, with a constant value for $E=2.2 \times 10^{-4}$, channel centerline change is driven by the excess velocity. Figure 5-2 shows the results of excessive velocity from both 
models, relative to the channel centerline. Line ' $a$ ' indicates the location of the minimum velocity excess which is slightly upstream of the inflection point of the streamline.

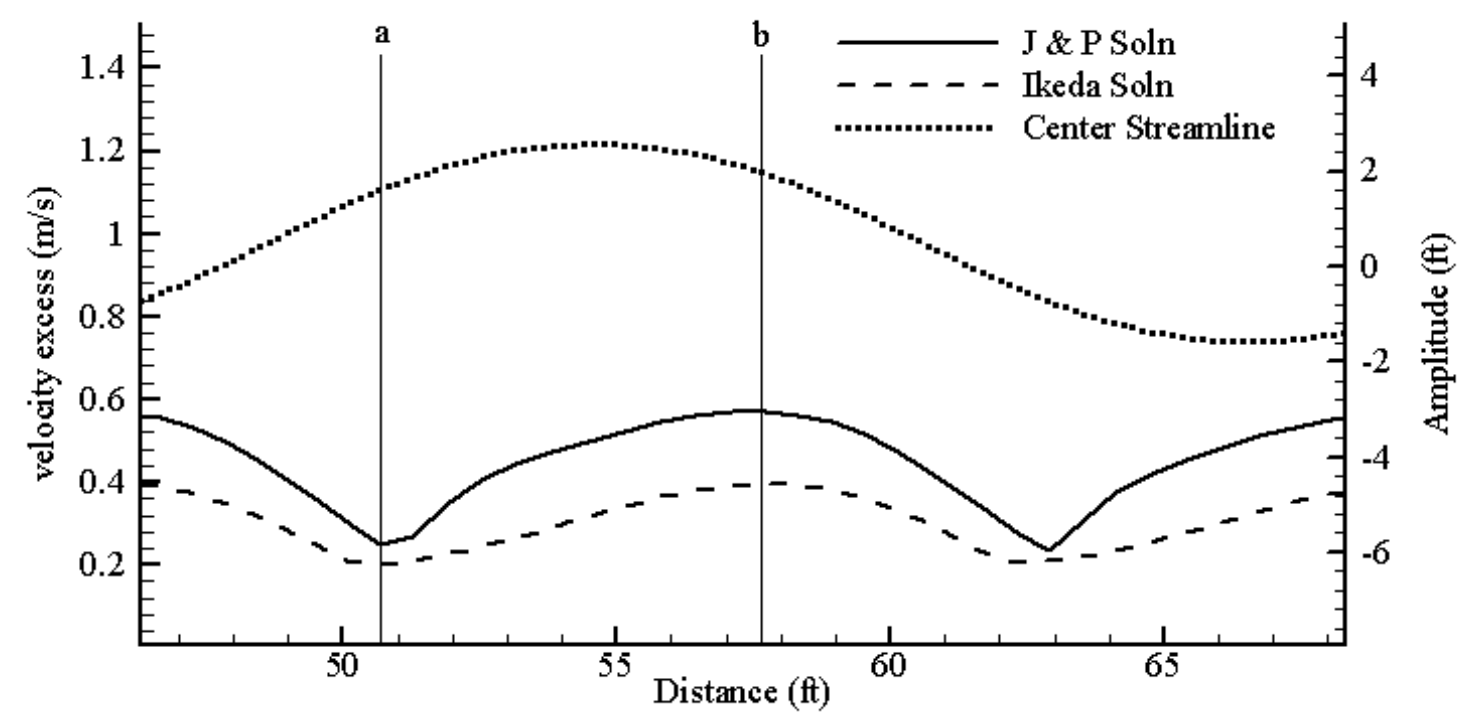

Figure 5-2: Excess Velocity Results of Flow Field Models Johannesson and Parker (1989b) and Ikeda (1981) for Initial Sine Generated Curve

Line ' $b$ ' in Figure 5-2 indicates the location of the maximum excess velocity which corresponds to the location along the outer bank across the point bar from the entrance to the bend. The maximum excessive velocity occurs at the outer bank downstream of the apex. The maximum bank erosion occurs where the excessive velocity is maximum. The location of maximum bank erosion is consistent with the laboratory measurement.

In order to determine which of the resulting meandering planform most matches the experimental measurements, two approaches were taken to determine the errors of simulated results comparing to the measurements. First, as illustrated in Figure 5-1, the symmetrical nature of the experimental data permitted to identify each bend based on the intersections with the xaxis. Each channel planform consists of several bends that are located either above or below the $\mathrm{x}$-axis. Each bend is represented with a series of nodes along its centerline. These nodes of given $\mathrm{x}$ - and $\mathrm{y}$-values could then be used to determine several geometric characteristics of the bend, which are the maximum y-value for measuring the maximum lateral extension of the bend, average $y$-value for the averaged lateral extension of the bend, the change in x-value of the maximum $y$-value for the symmetry, the standard deviation for the sharpness/roundness, and skew of each bend for its upstream/downstream rotation. These bend characteristics permit a quantitative approach to determine the similarity of simulated and measured bends. For two individual bends, the closer these parameters are, the closer the channel centerlines are. For each individual bend, the errors between the simulated and measured maximum distance from the $\mathrm{x}$ axis, which are the y-values of nodes on the stream centerline were determined and shown in Figure 5-3 


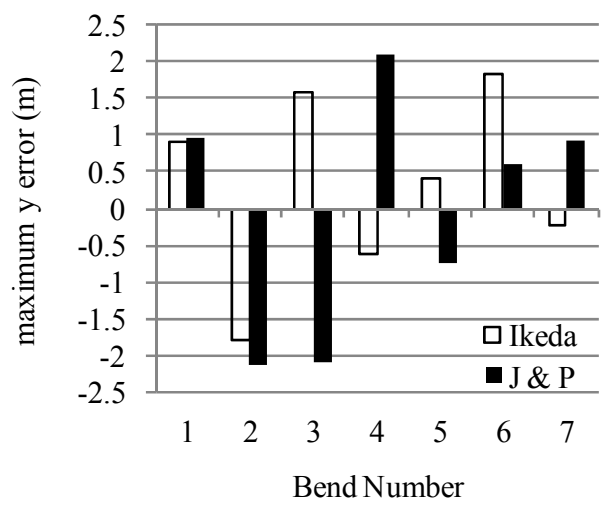

\section{Figure 5-3: Model Error for Distance from X-axis to Maximum Y-value for Each Bend Simulated for 32-hour Friedkin (1945) Simulation}

The Ikeda et al. (1981) model has consistently smaller errors with the exception at the sixth bend. Over the first two bends, both the Ikeda et al. (1981) and Johannesson and Parker's (1989b) models are consistent in their y-maximum value. Through the third and fourth bend, the models diverge, with Ikeda et al.'s (1981) model over-predicting the lateral expansion at the third bend and under-predicting at the fourth bend, while the Johannesson and Parker (1989b) in the converse. Both models over-predict the maximum y-value at the sixth bend.

The standard deviation of $y$-values over each bend quantifies the sharpness/roundness of the bend. The larger the standard deviation, the sharper the bend is. Figure 5-4 illustrates the model error for the standard deviation of each bend comparing to the 32-hour streamline of the Friedkin (1945) experiment.

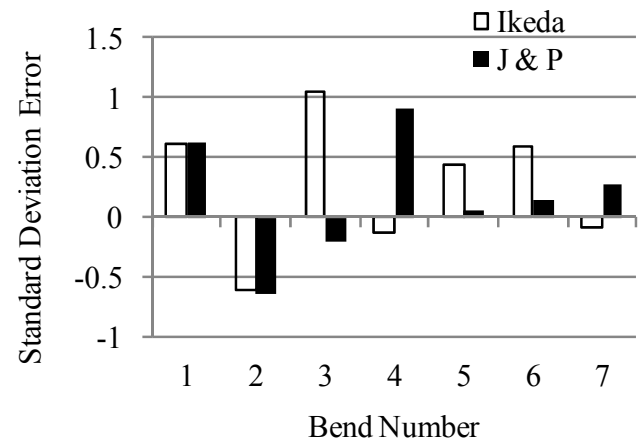

\section{Figure 5-4: Model Error for Deviation from the Mean Y-value for Each Bend Simulated for 32-hour Friedkin (1945) Simulation}

Both models yielded the similar standard deviations from the mean y-value, and therefore their errors are of the same magnitude over the first and the second bend. The Johannesson and Parker (1989b) model consistently was a better predictor of the average y value and the standard deviation.

The skew of a series of values is the third statistical moment and measures whether the variable is weighted to one side or the other relative to the mean value. Due to the asymmetry of river bends, the skew is one measure to quantify the degree of rotation of the meander bend. Figure 
5-5 shows the errors of skewness at each bend between the simulated results and the measurements.

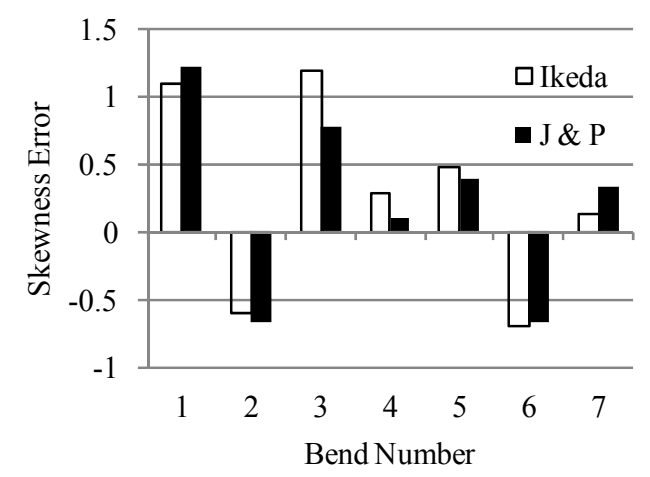

Figure 5-5: Model Error for Skew of Y-values for Each Bend Simulated for 32-hour Friedkin (1945) Simulation

Both models yielded nearly identical results of the skewness, and were also of a similar magnitude. Figure 5-6 shows the skewness values of simulated and observed data for each bend.

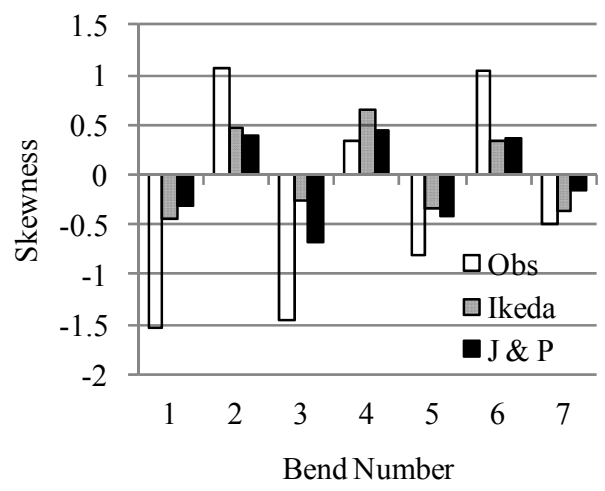

Figure 5-6: Model Results for Skew of Y-values for Each Bend Simulated for 32-hour Friedkin (1945) Simulation

There is a great deal of variation in the observed data; however, both models yielded skewness values of the same sign and magnitude as the observed data. This phenomenon indicated the randomness of bank erosion and consequently, the meandering planform migration.

Second, the overall model error was also determined by comparing the Mean Squared Error along the entire stream line (Table 5-2). 


\section{Table 5-2: Mean Squared Error Values for Ikeda (1981) Model and Johannesson \& Parker (1989b) Models}

Mean Squared Error Values for Ikeda (1981) and Johannesson and Parker (1989b) models.

Model

MSE

Ikeda (1981)

3245.40558

Johannesson and Parker (1989b)

3426.20621

Due to the complex geometries and coordinate conversions, it was found that a comparison of $y-$ values at specific points along the stream was the most feasible to determine model errors. A linear interpolation between nodes found in orthogonal coordinates was used to find y-values at the points of observed data Figure 5-7. Differences between the observed and simulated data can then be determined based on the differences of y-values at the same location.
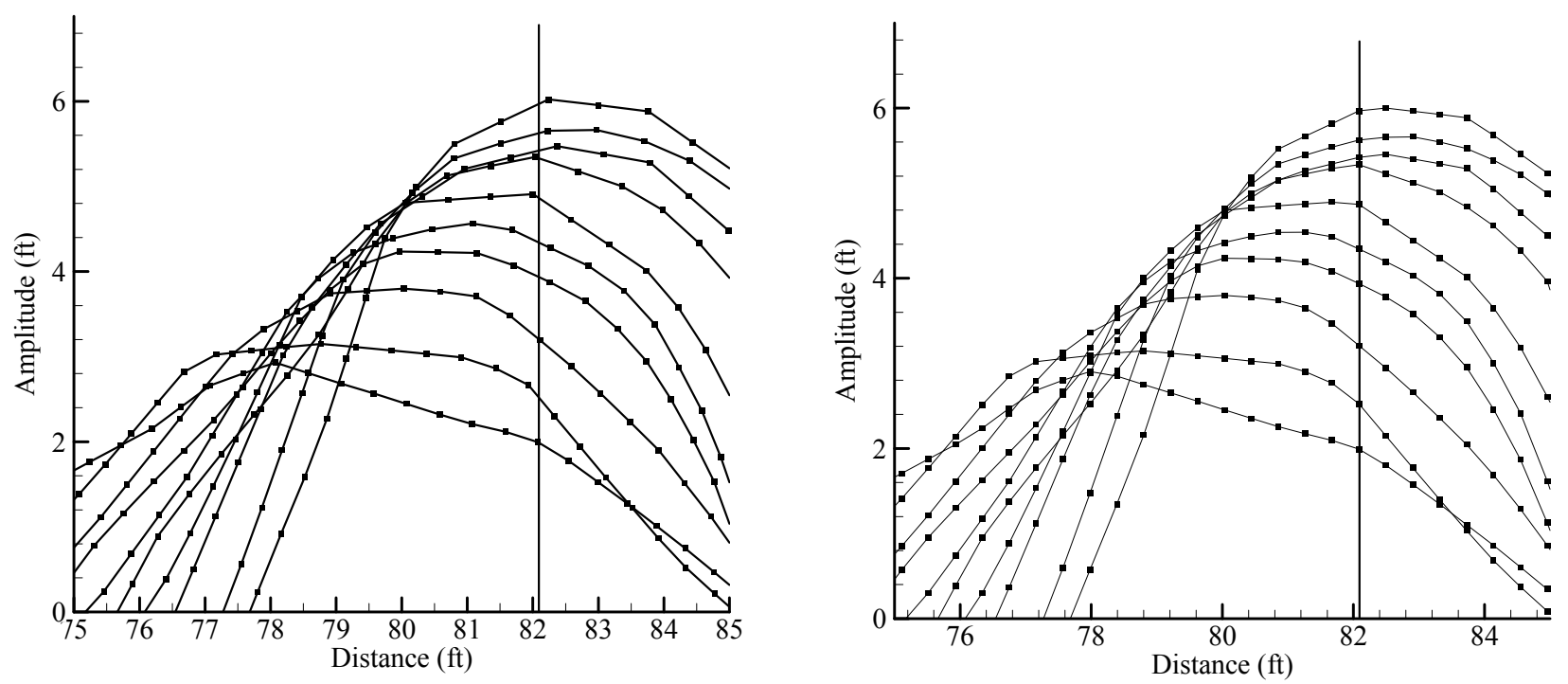

Figure 5-7: Interpolation from Curvilinear to Cartesian Coordinates

\subsection{Simulated Results from Monte Carlo Simulation}

If treating the bank erosion coefficient as a random variable, a stochastic simulation is needed to accurately predict the evolution of meandering channels. Results illustrated from the deterministic models showed the MSE from the Ikeda et al. (1981) model is less than that of the Johannesson and Parker (1989b) model. However, other bend characteristics indicated the Johannesson and Parker (1989b) model yielded better predictions of bend amplitude and skewness. This attribute supports the uncertainty in the bank erosion coefficient used in the deterministic model. The Monte Carlo simulation using a stochastic bank erosion coefficient is necessary. This study represents the bank erosion coefficient as a random variable and assumes its probabilistic density function satisfies either uniform or normal distribution. The linear bank coefficient used in the models is a proxy for the uncertainty associated with bank shear stress, soil composition, role of vegetation, and turbulence associated with bend flows. Figure 5-8 shows the results of the one thousand iterations given a $10 \%$ variation from the mean calibrated value used in the deterministic model. 


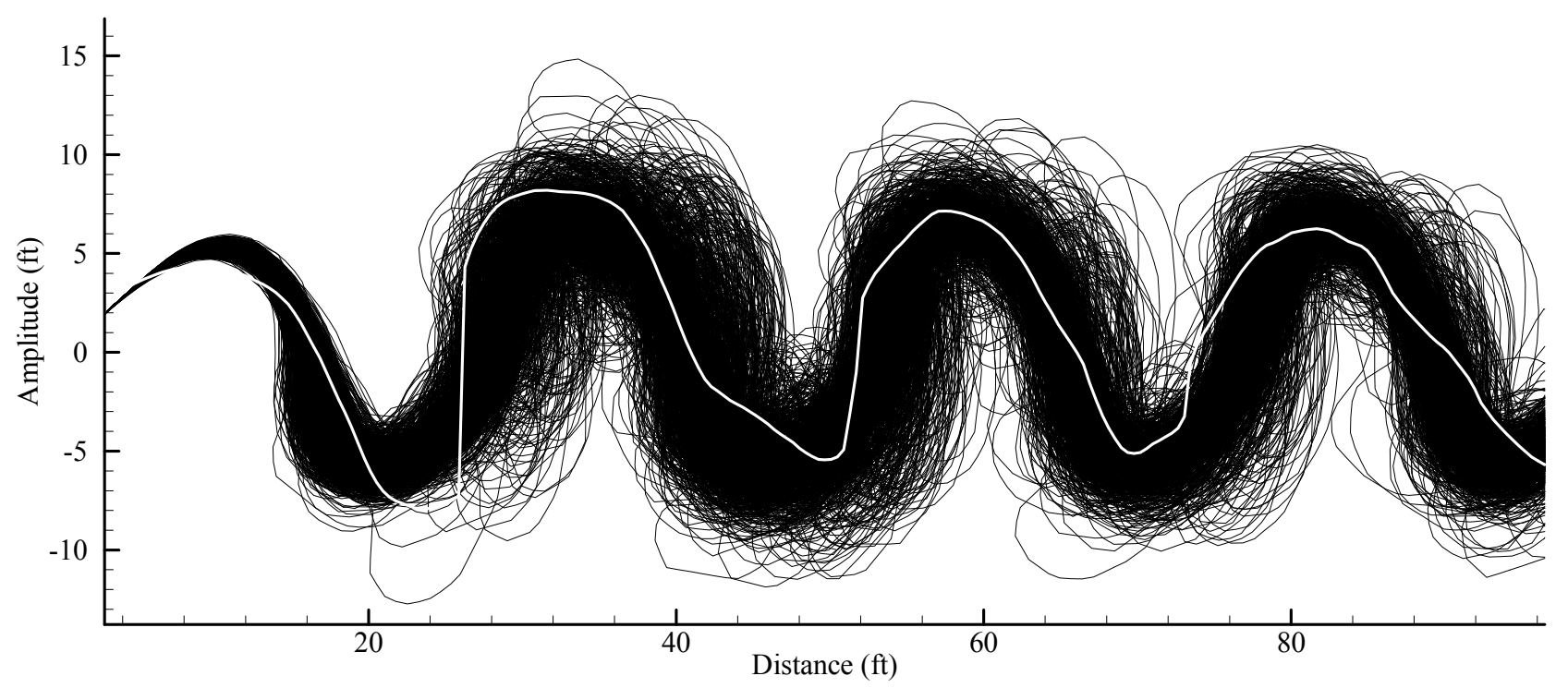

Figure 5-8: 1000 Iterations of Ikeda et al. (1981) Model with $10 \%$ Variability from 32 -hour Calibrated Value

By including all the y-values at each point along the stream line, both the average y-value of the 1000 iterations and the $95 \%$ confidence interval can be determined. The results of both statistics were shown in Figure 5-9 for the Ikeda et al. (1981) model, and in Figure 5-10 for the Johannesson and Parker (1989b).

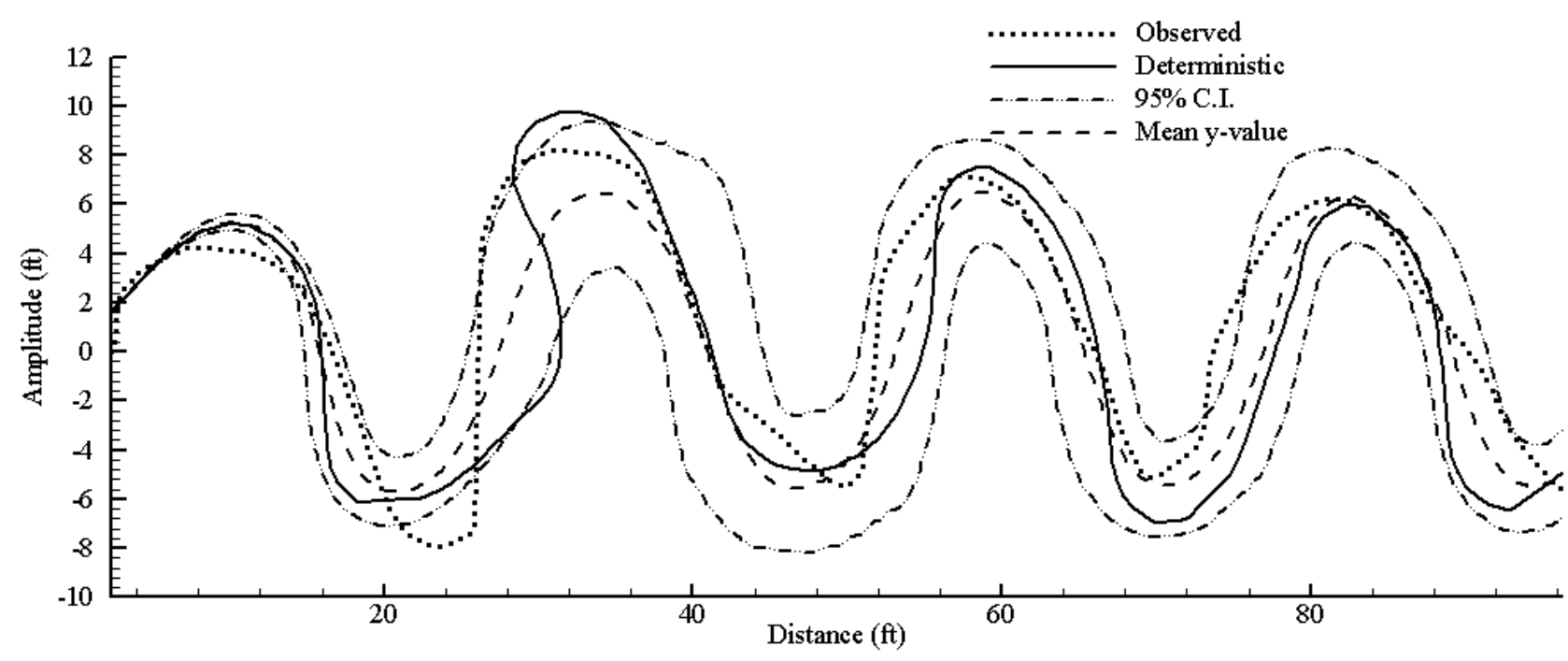

Figure 5-9: Results of Monte Carlo Analysis of 32-hour Calibrated Model with Ikeda (1981) Solution 


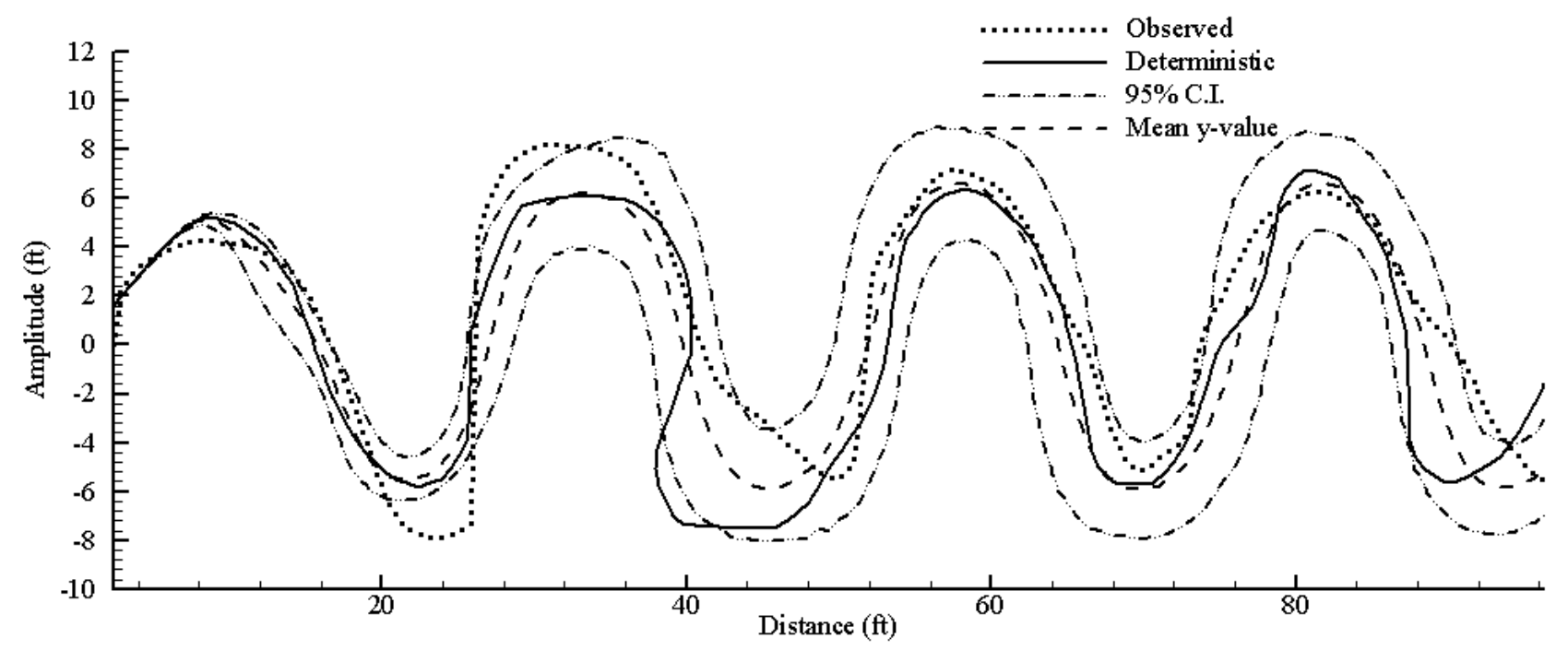

\section{Figure 5-10: Results of Monte Carlo Analysis of 32-hour Calibrated Model with Johannesson and Parker (1989b) Solution}

The errors of the maximum and standard deviation of y-values and skewness for each bend of the simulated stochastic mean channel were compared with the deterministic solutions in Figure 5-11, Figure 5-12, and Figure 5-13. With few exceptions, the average center streamline from the Monte Carlo simulation has less error than the deterministic solution. The one major exception is the prediction of the maximum y-value of the first and second bends (Figure 5-11).

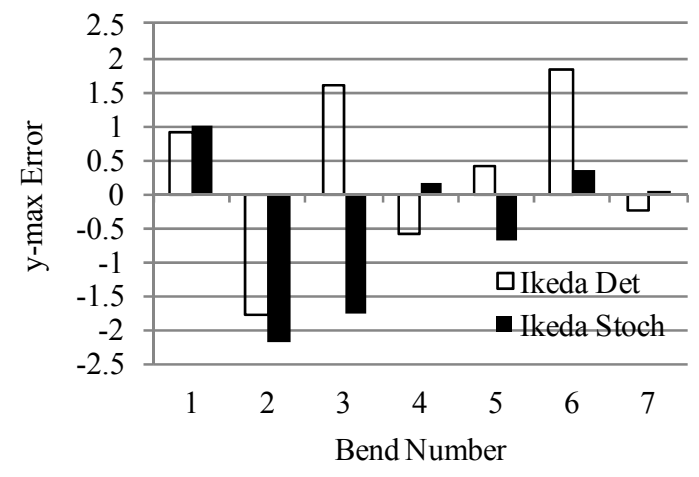

Figure 5-11: Comparison of Deterministic Model and Average Y-Max Value from Monte Carlo Simulation 


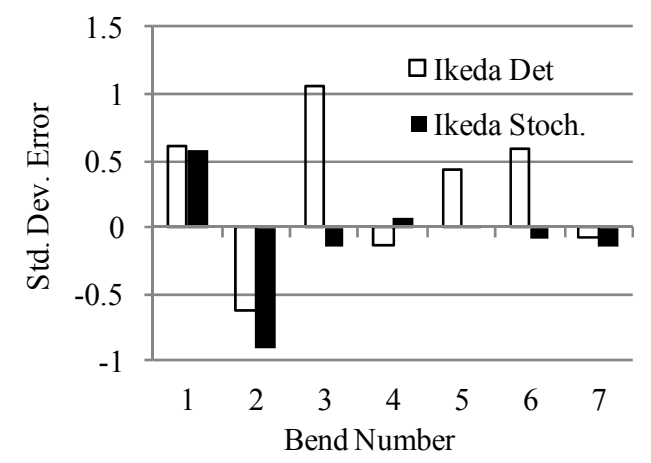

Figure 5-12: Comparison of deterministic model and standard deviations of average $y$-value from Monte Carlo simulation

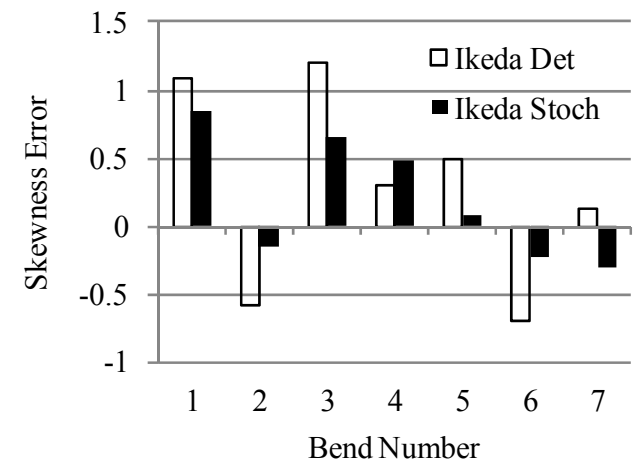

Figure 5-13: Comparison of Deterministic Model and Skewness of Average Y- Value from Monte Carlo Simulation

Assuming both normal and uniform distributions of bank erosion coefficient using Ikeda et al.'s (1981) flow model, the results are shown in Figure 5-14. Both distributions yielded nearly the same mean channel and slightly different $95 \%$ C.I. bounds. The measured channel centerline was within the $95 \%$ C.I. for both distributions. This perhaps indicates that the distribution function of the bank erosion coefficient has minor impacts on the mean simulated results. 


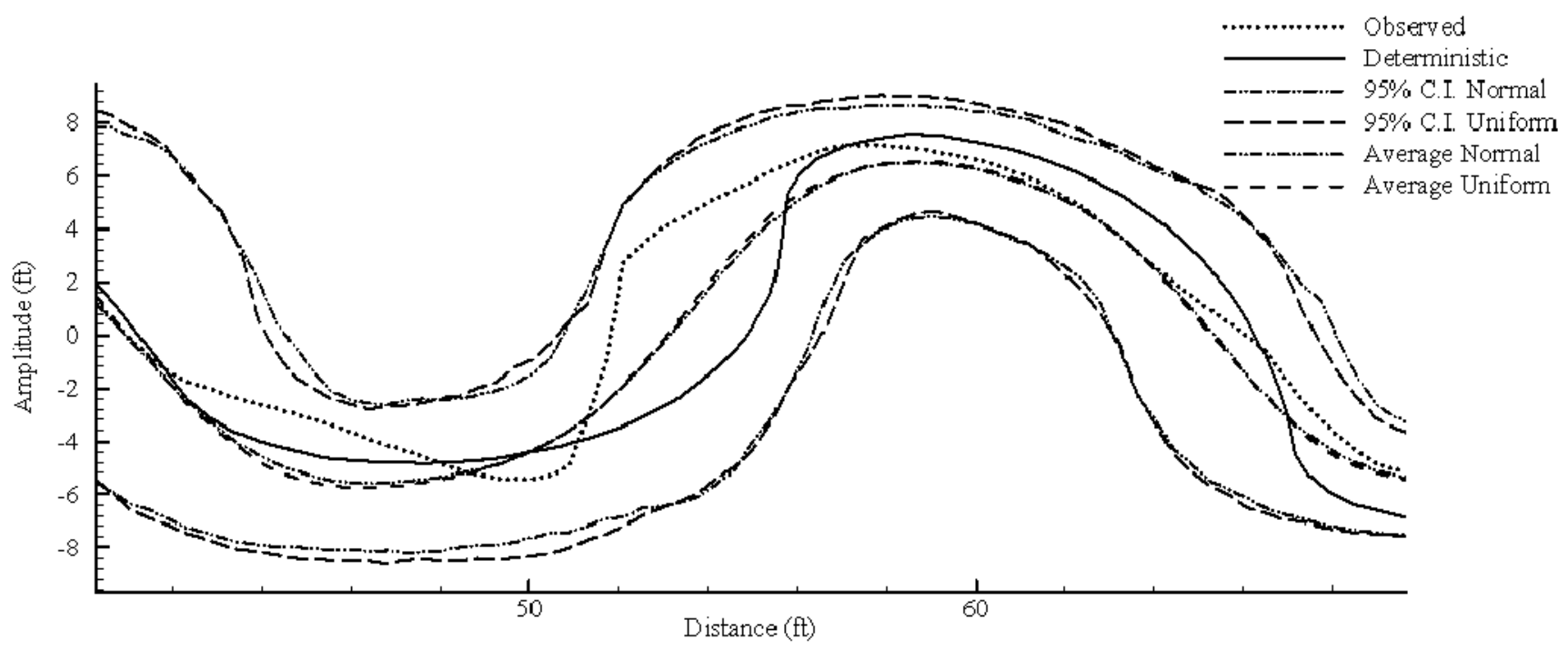

Figure 5-14: Bends 4 and 5 of 32-hour Simulation with Results from Both Uniform and Normal Distributions

\section{Discussion}

Several conclusions emerge from this study. First, the computational expense associated with the additional complexity of the Johannesson and Parker (1989b) model do not significantly improve the overall model performance. In fact, this study showed that the simpler Ikeda et al. (1981) model performed better using the cited performance metrics. While other authors have reported modifying or merging the two models in unique ways (Wallick, 2006; Constantine, 2009), often reduced the complexity, this simulation used the full analytical solution found by Johannesson and Parker (1989b). These hybrids will have smaller computational cost, but any possibility of improved results remains unknown. Figure 6-1 clearly indicates that the models do not produce a symmetric planform, despite a constant value of . Authors have reported the need for significantly smoothing the stream centerlines, mainly by employing sequential cubic splines, and complex curvature calculations, neither of those were employed in this study which may have led to errors in velocity excess and therefore the estimation of planform evolution.

Modeling errors in simulating river meandering evolution is not trivial. While the meandering planform is best described in the curvilinear coordinate, constraints such as the node placement and distances between nodes, and the fact that these are continuous phenomenon estimated in discrete spatial and temporal data sets, make direct comparison difficult. Nevertheless, there are a variety of bend characteristics that are of interest to describe the geometry of an evolving meandering river planform. The characteristics qualifying bend geometry include the lateral expansion rate, the magnitude of rotation towards upstream or downstream, and the speed of bend upstream/downstream translation. The maximum y-value is clearly of interest because it measures the maximum lateral extension of the bend; however, this value in relation to the midpoint of the bend could be more interest to the modeler, which is an indicator of symmetrical geometry. The standard deviation of the y-values at each bend provides insight into how sharp or round the bend is. Therefore, the standard deviation is an excellent metric with which to compare the shape of bends. Bend skewness is a metric which provides both meaningful measure of simulation error and aid in predicting planform evolution. Up- and down-stream rotation is 
captured through the skewness measure. Despite the fact flow field was solved in the curvilinear coordinate, the mean squared error of the simulated planform with respect to the observed data in the Cartesian coordinate is believed to be a good estimate of overall model error. In the case of a natural river where the $\mathrm{x}$ axis is not aligned with the downstream direction, the channel center axes orientation needs to be defined based on the alignment of each bend.

The Monte Carlo simulation of meander planform evolution using the linear bank erosion equation is a practical and realistic tool. Due to the variety and profundity of uncertainties associated with the linear bank erosion coefficient, , representing those uncertainties within the modeling framework is critical. Regardless of the fact that the average y-values from the Monte Carlo simulation were better estimates of observed data, the strength in this methodology lies in the ability to define confidence intervals within which the meandering planform evolves.

Although the entire observed planform is not within those confidence intervals, the vast majority (over 90\%) of that planform is found within the 95\% confidence interval. Those areas not within the confidence intervals are almost exclusively in the upper portion of the laboratory stream. These first few bends are somewhat anomalous, as the upper stream was significantly influenced by the entrance boundary condition.

Figure 6-1 shows the evolution of the laboratory stream produced by Friedkin (1945). Of note is the relative equilibrium that the planform takes after just 32 hours. The subsequent planforms do not differ significantly in amplitude, skew, or translation, suggesting the stream has reached regime conditions and is in a state of dynamic equilibrium. Therefore, when calibrating to the 32-hour planform, those parameter values could not be used to predict future planforms, calling in to question the calibration using historical records often used with the linear bank erosion model. These results suggest that a combination of those empirical models based on the overall meander river characteristics, flow, and sediment parameters, along with the linear bank erosion model using the Monte Carlo simulation is most appropriate to predict meandering channel evolution.

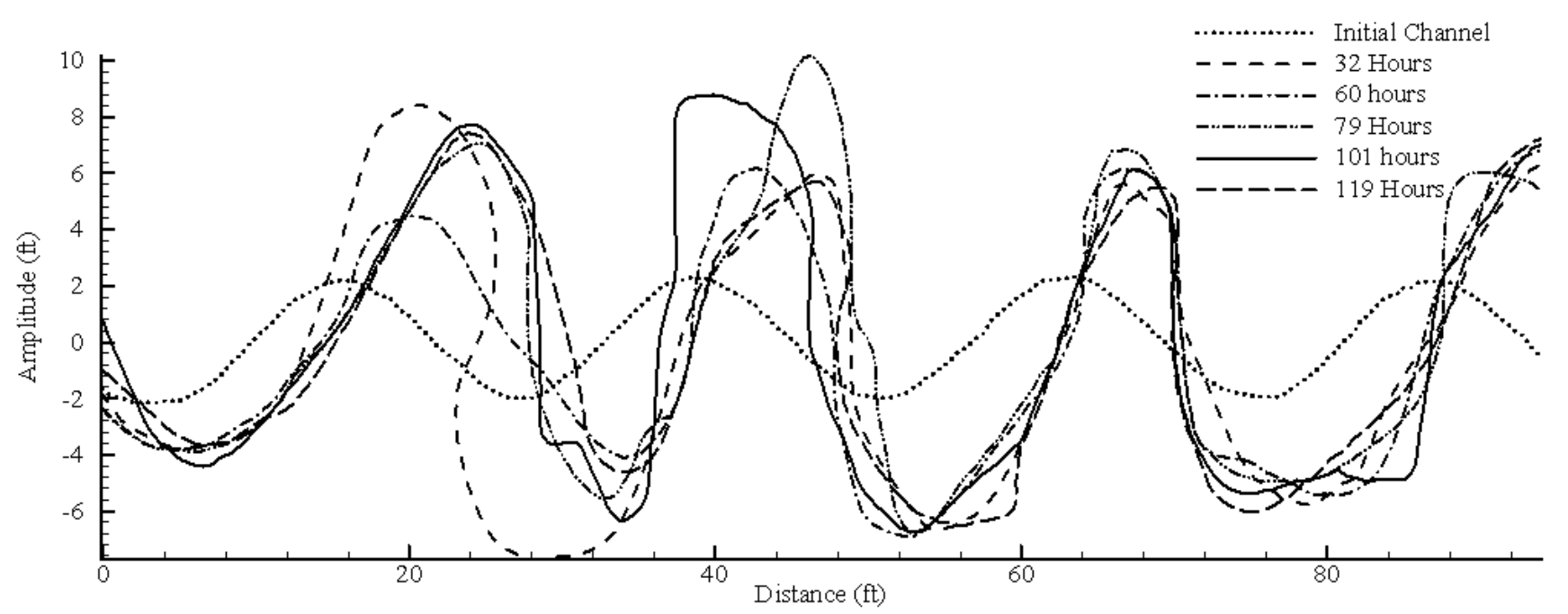

Figure 6-1: Planform Evolution of Friedkin (1945) Experiments 


\section{Conclusions}

This paper reported one dimensional numerical simulation of meandering evolution using deterministic and stochastic models. The $1^{\text {st }}$ order solutions of Navier Stokes equation in the curvilinear coordinate by Ikeda et al. (1981) and Johannesson and Parker (1989b) were used for determining the excess velocity. The bank erosion rate is assumed linearly proportional to near bank excess velocity. The deterministic model adopted a constant bank erosion coefficient for the entire simulation reach, while the stochastic model treated the bank erosion coefficient as a random variable satisfying either uniform or normal distribution. For the deterministic model, Johannesson and Parker (1989b)'s model predicted better bend characteristics than the results of Ikeda et al. (1981)'s model although errors from both models exceeds 50\%. This strongly suggested the limitation and incapability of deterministic models. On the other hand, the stochastic model yielded a $95 \%$ confidence interval bound that nearly bounds $90 \%$ of the observed channel centerline. The mean centerline from the stochastic model is within $30 \%$ errors when comparing to observed data. These results indicated that meandering migration process is a stochastic process that requires the Monte Carlo simulation to realistically model its evolution process. 


\section{References}

Ashworth P., Bennett, S., Best, J., and McLelland, S., 1996, "Coherent Flow Structures in Open Channels," John Wiley and Sons, Chichester, UK.

Box, G.E.P. and Mervin E. Muller, 1958. A Note on the Generation of Random Normal Deviates, The Annals of Mathematical Statistics, 29(2) pp. 610-611

Braudricka C.A., W.E. Dietricha, G.T. Leverichb, and L.S. Sklarb. 2009. Experimental evidence for the conditions necessary to sustain meandering in coarse-bedded rivers. Proceedings of the National Academy of Sciences of the United States of America, 2009 Oct 6; 106(40): 16936-41

Chang, H.H. 1988. On the cause of river meandering. International Conference on river regime, Paper C1. 18-20 May, 1988. Wallingford, England.

Cheng N. and Law, A. W., 2003. Fluctuations of turbulent bed shear stress. J. Hydraul. Eng., 129(1), 126130.

Constantine, C.R., Dunne, T., and Hanson, G.J., 2009. Examining the physical meaning of the bank erosion coefficient used in meander migration modeling. Geomorphology 106, 242-252.

Crosato, A., 1990. Simulation of meandering river processes, communications on hydraulic and geotechnical engineering, Technical report, Civil Engineering Department, Delft University of Technology.

Darby, Steven E. and Colin R. Thorne. (1993). Approaches to Modeling Width Adjustments in Curved Alluvial Channels. US Army European Research Office. Final Report February 1993.

Darby, S.E., Thorne, C.R., 1994. Prediction of tension crack location and riverbank erosion hazards along destabilized channels. Earth Surf. Process. Land., 19, 233-245

Darby, S. E. and Thorne, C. R., 1996. Development and testing of riverbank-stability analysis. J. Hydraul. Eng., 122(8), 443-454.

Darby, S. E., Alabyan, A. M., Van De Wiel, M J., 2002. Numerical simulation of bank erosion and channel migration in meandering rivers. Water Resour. Res., 38(9), 2-1 2-12.

Davies, T.R.H., and Tinker, C.C., 1984, "Fundamental Characteristics of Stream Meanders," Geological Society of America Bulletin, Vol. 95, No. 5, pp. 505-512.

Dietrich, W. E. \& Smith, J. D. (1983) "Influence of the point bar on flow through curved channels", Water Resources Research, 19(5), 1173-1192.

Duan, G. H., 1998. Simulation of alluvial channel migration processes with a two-dimensional numerical model, Dissertation, the Center for Computational Hydroscience and Engineering, the University of Mississippi, University, Mississippi. 
Duan, J. G., 2001. Discussion of “numerical analysis of river channel processes with bank erosion”, J. Hydraul. Eng., 127(8), 702-703.

Duan, J.G., 2005. Analytical approach to calculate the rate of bank erosion, J. Hydraul. Eng., 131(11), 980-990.

Duan, J.G. and Julien, P., 2005. Numerical simulation of the inception of meandering channel, Earth Surf. Process. Landf., 30, 1093-1110.

Duan, J. and Barkdoll, B., 2008. Surface-based fractional transport predictor: deterministic or stochastic, J. Hydraul. Eng., 134(3), 350-353.

Engelund, F., 1974. Flow and Bed Topography in Channel Bends. J. Hydraul. Div., 100(11), 1631-1648.

Ferguson, R. I. (1977). “Meander migration: equilibrium and change.” in River Channel Changes, edited by K. J. Gregory, Wiley Interscience, New York, 237-248.

Ferguson, R. I. (1983). "Kinematic model of meander migration." in River Meandering, edited by Elliott, C. M., New York, ASCE, 942-951.

Friedkin, J.F., 1945. A Laboratory Study of the Meandering of Alluvial Rivers. U.S. Army Engineers Waterways Experiment Station, Vicksburg, MS.

Gottlieb, L., 1976. Three-dimensional flow pattern and bed topography in meandering channels. Series Paper 11, Institute of Hydrodynamics and Hydraulic Engineering, Technical University of Denmark, Copenhagen, Denmark.

Gustavson, T.C. 1978. Bed forms and stratification types of modern gravel meander lobes, Nueces River, Texas. Sedimentology (1978) 25, 401-426

Gyr, A. 2010. The Meander Paradox-A Topological View. Applied Mechanics Reviews. Vol. 63, 020801-1-020801-12.

Hasegawa, K. and Ito, H., 1978. Computer simulations on meander channel changes. Proc., Hokkaido Branch, Japan Society of Civil Engineering, 34.

Hasegawa, K.,1989. Universal bank erosion coefficient for meandering rivers. J. Hydraul. Eng. 115, 744765.

Hooke, R. le B. (1975) "Distribution of sediment transport and shear stress in a meandering bend", Journal of Geology, 83, 543-565.

Hooke, J.M. and Rohrer, W., 1979. Geometry of alluvial fans: Effect of discharge and sediment size. Earth Surf. Process. Land., 4, 147-166.

Huang, H.Q, Chang, H.H. and Nanson, G.C. (2004). Minimum energy as a hydrodynamic principle and as an explanation for variations in river channel pattern. Water Resources Research, W04502, 2004. 
Ikeda, S., 1975. On secondary flow and bed profiles in alluvial curved open channels. Proceedings of the XVIth JAHR Congress, Sao Paolo.

Ikeda, S., Parker, G. and Sawai, K., 1981. Bend theory of river meanders: Part I, Linear development. J. of Fluid Mech., 112, 363-377.

Ikeda, S., and Nishimura, T., 1986. Flow and bed profile in meandering sand-silt rivers. J. Hydraul. Eng., $112(7), 562-579$.

Jefferson, W.S. 1902. Limiting Width of Meander Belts. National Geographic Magazine, 13, 373-383, 1902.

Johannesson, H., 1985. Computer Simulation migration of meandering rivers. Thesis presented to the Univeristy of Minnesota, at Minneapolis, in partial fulfillment for the degree of Master of Science.

Johannesson, H., and Parker, G., 1989a. Secondary flow in mildly sinuous channel. J. Hydraul. Eng., 115(3), 289-308.

Johannesson, H., and Parker, G., 1989b. Velocity redistribution in meandering rivers. J. Hydraul. Eng., 115(8), 1019-1039.

Khatsuria, R. 2008. How and Why Rivers Meander (Part 1). Hydrotopics. http://hydrotopics.wordpress.com/

Kikkawa, H., Ikeda, S., and Kitagawa, A., 1976. Flow and Bed Topography in Curved Open Channels. J. Hydraul. Div., 102(9), 1327-1342.

Kitanidis, P. K. \& Kennedy, J. F. (1984) "Secondary current and river meander formation", Journal of Fluid Mechanics, 144,

Komatsu, G. and V.R. Baker. 1994. Meander properties of Venusian Channels. Geology V. 22, 67-70.

Langbien, W.B. and Leopold, L.B., 1966. River Meanders- Theory of Minimum Variance. Physiographic and Hydraulic Studies of Rivers, Geologic Survey Professional Paper 422-H. 1966

LaPointe, M. F. \& Carson, M. A. (1986) "Migration patterns of an assymetric meandering river: the Rogue River, Quebec". Water Resources Research, 22(5), 731-743.

Larsen, E.W., Greco, S.E., 2002. Modeling channel management impacts on river migration: a case study of Woodson Bridge State Recreation Area, Sacramento River, California, USA. Environ. Manage. 30, 209-224.

Leopold, Luna B. and Wolman, M.G. 1960. River Meanders: Bulletin Geologic Society of America, v.71 p. $769-794$.

Leopold, Luna B., Wolman, M.G., and Miller, J.P. 1964. Fluvial Processes in Geomorphology, San Francisco, W.H. Freeman and Co., 522p. 
Lopez, F. and Garcia, M. H., 1999. "Wall similarity in turbulent open channel flow.” J. Engrg. Mech., 127(7), 789-796.

Marani, M., S. Lanzoni, and D. Zandolin. 2002. Tidal Meanders. Water Resources Research. Vol. 38, No. $11,1225$.

Markham, A. J. (1990) "Flow and sediment processes in Gravel-Bed river bends ", Thesis sSubmitted to the University of London in full requirements of the degree of Doctor of Philosophy.

Micheli, E.R., and J.W. Kirchner, 2002. Effects of wet meadow riparian vegetation on streambank erosion. 1. Remote sensing measurements of streambank migration and erodibility. Earth Surf. Process. Land. 27, 627-639.

Micheli, E.R., Kirchner, J.W., Larsen, E.W., 2004. Quantifying the effects of riparian forest versus agricultural vegetation on river meander migration rates, central Sacramento River, California, USA. River Res. Appl. 20, 537-548.

Moorhead, Kevin K., David W. Bell, Rachael N. Thorn. 2008. Floodplain Hydrology After Restoration of a Southern Appalachian Mountain Stream. Wetlands 28(3):632-639. 2008

Nakano D. and F. Nakamura. 2007. 'The significance of meandering channel morphology on the diversity and abundance of macroinvertebrates in a lowland river in Japan'. Aquatic Conservation: Marine and Freshwater Ecosystems. Vol 18. No. 5. Pg. 780-798. 2008

Nelson, J. M. (1988) "Mechanics of flow and sediment transport over non-uniform erodible beds", Thesis presented to the University of Washington in partial fulfilment of requirements of the degree of Doctor of Philosophy.

Osman, A. M. and Thorne, C. R., 1988. Riverbank stability analysis. 1: Theory. J. Hydraul. Eng., 114(2), 134-150.

Parker, G. 1976. On the cause and characteristic scales of meandering and braiding in rivers. J. Fluid Mech. Vol. 76, No. 3. 457-480.

Parker, G., Sawai, K., and Ikeda, S., 1982. Bend theory of river meanders: Part II, Nonlinear deformation of finite-amplitude bends. J. Fluid Mech., 115, 303-314.

Parker, G., 1982. Stability of the channel of the Minnesota River near State Bridge No. 93, Minnesota," Project Report No. 205, St. Anthony Falls Hydr. Lab Univ. of Minnesota, Minneapolis, Minn., $33 \mathrm{pp}$.

Pizzuto, J.E., Meckelnburg, T.S.,1989. Evaluation of a linear bank erosion equation.Water Resour. Res. 25, 1005-1013.

Rozovskii, L. L. (1957) "Flow of water in bends of open channels", translated by the Israel Programme for Scientific Translation (1961). 233pp. 
Seim H.E., Blanton J.O., Elston S.A., 2009. The effect of secondary circulation on the salt distribution in a sinuous coastal plain estuary: Satilla River, GA, USA. Continental Shelf Research, 29(1), 1528.

Smith, J. D., and McLean, S. R. (1984). "A model for flow in meandering streams." Water Resour. Res., 20(9), 1301-1315.

Smith, S.A., 1987, "Gravel Counterpoint Bars: Examples from the River Tywi, South Wales," SEPM, Spec. Publ. No. 39, F.G. Ethridge, R.M. Flores, and M.D. Harvey (eds.), p. 75-81.

Suga, K., 1963. On local scour at river bends. Tech. Memo Public Works Res. Inst., Min. of Const. Japan, $5(4)$.

Sun, T., Meakin, P., JØssang, T., and Schwarz, K., 1996. A simulation model for meandering rivers. Water Resour. Res., 32, 2937-2954.

Thompson, J.J., 1876, "On the Windings of Rivers in Alluvial Plains," Proceedings of the Royal Society of London, 25, 5-8.

Thorne, C. R. (1978) "Processes of bank erosion in river channels ", Thesis submitted to the University of East Anglia in complete fulfilment of the requirements of the degree of Doctor of Philosophy. $447 \mathrm{pp}$.

Thorne, C.R., 1992, "Bend Scour and Bank Erosion on the Meandering Red River, Louisiana," In: P.A. Carling and G.E. Petts (eds.), Lowland Floodplain Rivers: Geomorphological Perspectives, John Wiley and Sons, Chichester, UK, 95-115.

US Army Corps of Engineers (1981). The Streambank Erosion Control Evaluation and Demonstration Act of 1974, Section 32, Public Law 93-251. Final Report to Congress, Waterways Experimental Station, Vicksburg, Mississippi.

Van Bendegom, L. (1947) “Eenige Beschouwingen over Riviermorphologie en rivierverbetering.” De Ingenieur, Vol 59. No. 4, pgs 1-11.

Wallick, J.R., Lancaster S.T., and Bolte, J.P., 2006. Determination of bank erodibility for natural and anthropogenic bank materials using a model of lateral migration and observed erosion along the Willamette River, Oregon, USA. River Res. Applic. 22, 631-649.

Yen, C. L. \& Yen, B. C. (1971) "Water surface configuration in channel bends", Journal of the Hydraulics Division of the ASCE, 97(HY2), 303-321.

Zimmerman, C. \& Kennedy, J. F., 1978. Transverse bed slope in curved alluvial streams. J. Hydraul. Div. 104(1), 33-48. 


\section{Distribution}

1 MS 0899 Technical Library, 9536 (electronic copy)

$1 \quad$ MS0359 LDRD Office, 1911 (electronic copy)

1 MS 1137 Stephanie Kuzio, 6926 (electronic copy)

1 MS 1137 Vincent Tidwell, 6926 (electronic copy)

Ari Posner (electronic copy)

University of Arizona 